\title{
A disjunct eddy accumulation system for the measurement of BVOC fluxes: instrument characterizations and field deployment
}

\author{
G. D. Edwards ${ }^{1}$, D. K. Martins ${ }^{2, *}$, T. Starn ${ }^{3}$, K. Pratt ${ }^{2}$, and P. B. Shepson ${ }^{2,4}$ \\ ${ }^{1}$ Department of Chemistry, Eastern Michigan University, Ypsilanti, MI 48197, USA \\ ${ }^{2}$ Department of Chemistry, Purdue University, West Lafayette, IN 47907, USA \\ ${ }^{3}$ Department of Chemistry, West Chester University, West Chester, PA 19383, USA \\ ${ }^{4}$ Purdue Climate Change Research Center, Purdue University, West Lafayette, IN 47907, USA \\ *now at: Department of Meteorology, Pennsylvania State University, University Park, PA 16802, USA
}

Correspondence to: G. D. Edwards (gedward4@emich.edu)

Received: 20 January 2012 - Published in Atmos. Meas. Tech. Discuss.: 4 April 2012

Revised: 7 August 2012 - Accepted: 16 August 2012 - Published: 5 September 2012

\begin{abstract}
Biological volatile organic compounds (BVOCs), such as isoprene and monoterpenes, are emitted in large amounts from forests. Quantification of the flux of BVOCs is critical in the evaluation of the impact of these compounds on the concentrations of atmospheric oxidants and on the production of secondary organic aerosol. A disjunct eddy accumulation (DEA) sampler system was constructed for the measurement of speciated BVOC fluxes. Unlike traditional eddy covariance (EC), the relatively new technique of disjunct sampling differs by taking short, discrete samples that allow for slower sampling frequencies. Disjunct sample airflow is directed into cartridges containing sorbent materials at sampling rates proportional to the magnitude of the vertical wind. Compounds accumulated on the cartridges are then quantified by thermal desorption and gas chromatography. Herein, we describe our initial tests to evaluate the disjunct sampler including the application of vertical wind measurements to create optimized sampling thresholds. Measurements of BVOC fluxes obtained from DEA during its deployment above a mixed hardwood forest at the University of Michigan Biological Station (Pellston, MI) during the 2009 CABINEX field campaign are reported. Daytime (09:00 a.m. to 05:00 p.m. LT) isoprene fluxes, when averaged over the footprint of the tower, were $1.31 \mathrm{mg} \mathrm{m}^{-2} \mathrm{~h}^{-1}$ which are comparable to previous flux measurements at this location. Speciated monoterpene fluxes are some of the first to be reported from this site. Daytime averages were $26.7 \mu \mathrm{g} \mathrm{m}^{-2} \mathrm{~h}^{-1}$ for $\alpha$-pinene and $10.6 \mu \mathrm{g} \mathrm{m}^{-2} \mathrm{~h}^{-1}$ for $\beta$-pinene. These measured concentrations and fluxes were
\end{abstract}

compared to the output of an atmospheric chemistry model, and were found to be consistent with our knowledge of the variables that control BVOCs fluxes at this site.

\section{Introduction}

Biological volatile organic compounds (BVOCs) released from the biosphere have been shown to play a significant role in atmospheric chemistry (Guenther et al., 1993). Plants are estimated to emit greater than $1.2 \times 10^{12} \mathrm{~kg}$ of these BVOCs per year to the atmosphere, an estimated $40 \%$ of which are made up of one species, isoprene (2-methyl-1,3-butadiene, $\mathrm{C}_{5} \mathrm{H}_{8}$ ) (Guenther et al., 1995). Emission rates of isoprene are strongly correlated with ambient light and temperature (e.g., Loreto, 1997). The next largest contributors to the total BVOC flux are monoterpenes, molecules with the general formula $\mathrm{C}_{10} \mathrm{H}_{16}$, which include the species $\alpha$ - and $\beta$ pinene (Kesselmeier and Staudt, 1999; Lee et al., 2005). Isoprene is emitted by many broadleaf species, while monoterpenes are emitted from conifers as well as broad-leaved trees. Monoterpene emission rates appear to be largely controlled by temperature (e.g., Guenther et al., 1993; Arneth et al., 2008). These BVOCs are highly reactive due to their nature as unsaturated hydrocarbons. In the sunlit troposphere, hydroxyl radicals $(\mathrm{OH})$ can rapidly attack these molecules and add across the carbon-carbon double bonds, creating peroxy radical intermediates (e.g., Zhang et al., 2000). In the presence of nitrogen oxides $\left(\mathrm{NO}+\mathrm{NO}_{2}\right)$, the peroxy radicals

Published by Copernicus Publications on behalf of the European Geosciences Union. 
generate photochemical ozone via oxidation of $\mathrm{NO}$ to $\mathrm{NO}_{2}$ (Chamedies et al., 1973). Isoprene oxidation via this mechanism has been implicated in regional events of elevated tropospheric ozone (e.g., Biesenthal et al., 1997; Harrison et al., 2001). Similar mechanisms also describe the oxidation of monoterpenes to produce ozone (e.g., Kesselmeier and Staudt, 1999). In addition to their influence on the oxidative capacity of the atmosphere, BVOC oxidation products can contribute to secondary organic aerosol (SOA) formation (e.g., Makela et al., 1997; Kavouras et al., 1999; Griffin et al., 1999). BVOC-derived SOA represents a source of aerosol to the atmosphere that can impact both regional air quality and global climate (Andreae and Crutzen, 1997). The potential role of isoprene and other naturally emitted hydrocarbons in biosphere-climate chemistry feedbacks was summarized by Shallcross and Monks (2000) and Fuentes et al. (2001). Knowledge of speciated BVOC emission rates is essential to reduce uncertainties associated with predictions of BVOC concentrations and subsequent impacts on the SOA and ozone production on local, region and global scales.

The most common flux measurement reported to date is the (EC) approach (Baldocchi et al., 1995). In eddy covariance, it is necessary to utilize a method that measures BVOC concentration on a time scale corresponding to the smallest of the important eddies that carry the flux, i.e., up to $10 \mathrm{~Hz}$ (Baldocchi et al., 1995). However, for many trace-level species, this is often not feasible as current analytical techniques have insufficient response times. The current exceptions are proton transfer-reaction mass spectrometry, PTRMS, which has been used for isoprene flux measurements (e.g., Karl and Guenther, 2004; Warneke et al., 2005), and the Fast Isoprene Sensor (e.g., Westberg et al., 2001). However, PTR-MS cannot easily determine speciated monoterpene fluxes (Müller et al., 2009; Misztal et al., 2012) as these instruments tend measure the sum of all of the isobaric monoterpene species (e.g., Kim et al., 2009). Further, the Fast Isoprene Sensor suffers interference in environments where isoprene is not the dominant alkene (Edwards et al. 2007; Barket et al., 2001). To measure the fluxes of both isoprene and speciated monoterpenes, methods that enable fast sampling with off-line analysis have been developed. By using systems that accumulate the species of interest, the low ambient concentration of these molecules can be overcome. There are several types of accumulation-based flux measurements where samples are often accumulated and then analyzed. These include using the flux gradient method (e.g., Guenther et al., 1996; Pattey et al., 1999), relaxed eddy accumulation (REA) (e.g., Tani et al., 2002; Christensen et al., 2002; Lee et al., 2005; Kuhn et al., 2007) and, more recently, disjunct eddy accumulation (DEA) (e.g., Rinne et al., 2000, 2002; Turnipseed et al., 2009). The premise of DEA is similar to REA in that two segregated samples are taken based on the direction of the vertical wind. However, rather than sampling all eddies as in REA, in DEA a larger volume from a statistically representative and objectively collected set of eddies is sampled into an intermediate storage reservoir. The air is partitioned into updraft and downdraft reservoirs over some averaging period. This is based on the sign of the vertical wind and proportional to its magnitude. The average flux over the sampling period is related to the concentrations in the updraft and downdraft reservoirs as determined by analysis of these reservoirs off-line using a suitable analysis platform such as gas chromatography.

As a large part of the flux in the atmospheric surface layer is carried by relatively large eddies, Lenschow et al. (1994) showed that the disjunct sampling does not increase the statistical uncertainty of the flux values more than $8 \%$ if the time interval between samples is shorter than the appropriate integral timescale. However, often in DEA the integral timescale is actually shorter than the sample interval. In these cases the random error introduced depends on sample number; thus, with sufficiently large sample numbers the same accuracy can be achieved (Rinne and Ammann, 2012). A major advantage of the disjunct eddy accumulation techniques described in the literature is that they are direct flux measurements and do not depend on similarity assumptions, empirical relationships or derived correction constants. This makes the approach potentially less vulnerable to systematic errors, which can affect both gradient and REA measurements (Rinne et al., 2000). However, as described by Turnipseed et al. (2009), disjunct sampling allows longer time to process the samples, but increases the uncertainty of the measurements both with mechanically undisturbed wind measurements and relatively homogeneous conditions; DEA can be a viable approach for the flux measurements for a variety of important tracers of biogenic origin.

In this paper, a new DEA sampling system is described that has been used to measure both isoprene and speciated monoterpenes mixing ratios and fluxes. This differs from "true" disjunct eddy accumulation described in the literature in that it uses a dead-band sampling approach to measure BVOC flux. This variation has not previously been reported, and therefore our technique differs slightly from true DEA. Characterization of our DEA system is described both in the lab and the field. In addition, field measurements of ambient isoprene and monoterpene ( $\alpha$ - and $\beta$-pinene) concentrations and fluxes above a forest site in northern Michigan are reported. Here, our DEA system was deployed at the University of Michigan Biological Station (UMBS, Carroll et al., 2001) as part of the Combined Atmosphere-Biosphere Intensive Experiment (CABINEX) campaign (Bertman et al., 2012).

The UMBS region forest is a late successional growth forest, where the main tree species, aspen (a strong isoprene emitter), is at the end of its life cycle, and the forest is now undergoing a successional transition to a forest more substantially impacted by terpene emitters, such as white pine (Stearns and Likens, 2002; Bergen and Dronova, 2007). Thus, the ability to measure the impacts on and implications for local atmospheric chemistry above the forest during such 
transition is important, and represents a good opportunity to examine the differences in impacts of isoprene vis-à-vis monoterpenes. To our knowledge, DEA has only been utilized to measure both isoprene and speciated monoterpenes only once previously, by Rinne et al. (2002) for experiments in the Amazon. The deployment of our DEA system during CABINEX represents the first use of the disjunct accumulation technique for the purpose of determining both isoprene and monoterpene fluxes in a North American forest, and at one undergoing a successional transition.

\section{Theory of operation}

In (true) DEA, for a disjunctly sampled time series, the turbulent flux of a scalar, $c$, can be estimated as the covariance of the subset of data points and the vertical velocity component of the wind, $w$ (Rinne et al., 2000).

$F_{\mathrm{c}}=\left\langle w^{\prime} c^{\prime}\right\rangle_{\mathrm{disj}}=\frac{1}{N} \sum_{i=1}^{N} w^{\prime}\left(t_{i}\right) c^{\prime}\left(t_{i}\right)$.

Here, $N$ is the total number of disjunctly sampled points, and $w^{\prime}$ and $c^{\prime}$ are deviations from the mean of the vertical velocity $w$, and the scalar density $c$, respectively. The variable $t_{i}$ represents the $i$-th time component of an ensemble time average for the disjunct sample. Turnipseed et al. (2009) showed that, for continuous sampling, accumulated volumes $\left(V^{+}\right.$for updrafts and $V^{-}$for downdrafts) from each disjunctly isolated air sample that is stored in some initial storage reservoir can be dispensed into updraft or downdraft reservoirs at rates proportional to the instantaneous vertical wind. The total scalar flux can be related to the concentrations in these updraft and downdraft reservoirs where, under ideal conditions,

$F_{\mathrm{c}}=\left\langle w^{\prime} c^{\prime}\right\rangle_{\mathrm{disj}}=\frac{V^{ \pm}}{k N}\left(c^{+}-c^{-}\right)=\overline{\frac{\left|w_{\mathrm{disj}}^{\prime}\right|}{2}}\left(c^{+}-c^{-}\right)$.

Here, $V^{ \pm}$represents the total volume over the entire flux averaging period, $k$ is a constant relating the sampling flow rate and/or the dispense time to $w$, and $\bar{w}_{\text {disj }}$ is the mean vertical wind velocity during disjunct sampling. The variables $c^{+}$and $c^{-}$represent the concentrations of the scalar in the updraft or downdraft reservoirs. Under ideal conditions, $\bar{w}_{\text {disj }}=0$ and the volume collected as updrafts equals that of downdrafts. However, under real atmospheric conditions, $\bar{w}_{\text {disj }} \neq 0$, and unequal volumes are collected. The volume difference, $\Delta V$, is a function of the total volume collected, $V_{\text {tot }}$, where

$\Delta V=V^{+}-V^{-}=2 f V_{\text {tot }}$.

Here, $f$ is a scaling factor as described by Hicks and McMillen, (1984), calculated according to

$f=\left(\frac{V^{+}}{V_{\mathrm{tot}}}-\frac{1}{2}\right)$.
The mass $m$ in each accumulated reservoir can now be related to the ideal case $\left(m_{\mathrm{v}}\right)$ such that

$m^{+}=m_{\mathrm{v}}^{+}+\frac{\Delta V}{2} c^{+}=m_{\mathrm{v}}^{+}+V_{\mathrm{tot}} f c^{+}$

$m^{-}=m_{\mathrm{v}}^{-}+\frac{\Delta V}{2} c^{-}=m_{\mathrm{v}}^{-}+V_{\text {tot }} f c^{-}$.

Turnipseed et al. (2009) showed that, if $\bar{w}_{\text {disj }}$ and $\bar{c}_{\text {disj }}$ are the mean vertical wind and concentration of the scalar $c$ respectively, Eq. (2) now becomes

$F_{\mathrm{c}}=\left\langle w^{\prime} c^{\prime}\right\rangle_{\mathrm{disj}}=\frac{1}{k N}\left(m_{\mathrm{v}}^{+}-m_{\mathrm{v}}^{-}\right)+\bar{w}_{\mathrm{disj}}\left(\frac{\left(c^{+}+c^{-}\right)}{2}-\bar{c}_{\mathrm{disj}}\right)$.

Or, in terms of the density of the scalar, $c$, the average is taken from the absolute value of vertical wind velocities such that

$F_{\mathrm{c}}=\left\langle w^{\prime} c^{\prime}\right\rangle=\frac{\overline{\left|w_{\text {disj }}^{\prime}\right|}}{2}\left(c_{\mathrm{v}}^{+}-c_{\mathrm{v}}^{-}\right)+\bar{w}_{\text {disj }}\left(\frac{\left(c^{+}+c^{-}\right)}{2}-\bar{c}_{\text {disj }}\right)$.

\section{Lab characterizations}

Figure 1 shows a flow schematic of our DEA sampler together with the system dimensions. The system is housed in an all weather case (Pelican \#1600NF) to protect the sampler, while computer cooling fans (NMB-MAT \#7015 12V 0.28A) help to maintain optimum temperatures inside the case. During routine operation, ambient samples are acquired every $30 \mathrm{~s}$ with the system operating autonomously. All of the analog and digital input/outputs were controlled using LabVIEW 8.6 (National Instruments, Corp.) using customdesigned software. The sampling cycle begins by rapidly flushing ambient air through a $3.5 \mathrm{~m}, 0.95 \mathrm{~cm}$ I.D. inlet and through an intermediate storage reservoir(ISR) using a rotary vane vacuum pump (Gast, model 1023-101QG608X). The ISR consists of a heated $\left(T=60^{\circ} \mathrm{C}\right)$, PFAcoated, stainless steel cylinder of $300 \mathrm{~cm}^{3}$ internal volume. At pre-determined time intervals, the instantaneous value of the vertical wind is recorded and the control computer closes two $0.79 \mathrm{~cm}$ solenoid stop valves (Parker, model no. 7121SN21V00N0C111P3) upstream and downstream of the ISR to secure the sample. The magnitude and direction of the vertical wind is measured using a CSAT3 sonic anemometer (Campbell Scientific, Inc.) at a frequency of $10 \mathrm{~Hz}$. The flow rate through the ISR was measured to be 152 SLPM giving a residence time of air within the inlet tubing and ISR of 0.12 seconds during flushing. This lag was used to synchronize the DEA with the correct wind measurement; the control computer thus accounts for the delay associated with this transfer time from the inlet to the ISR before closing.

Samples are then taken from the ISR by directing the airflow through preconditioned glass-lined commercial sample cartridge traps $(10.2 \mathrm{~cm} \times 0.3 \mathrm{~cm}$ I.D. Scientific Instrument 


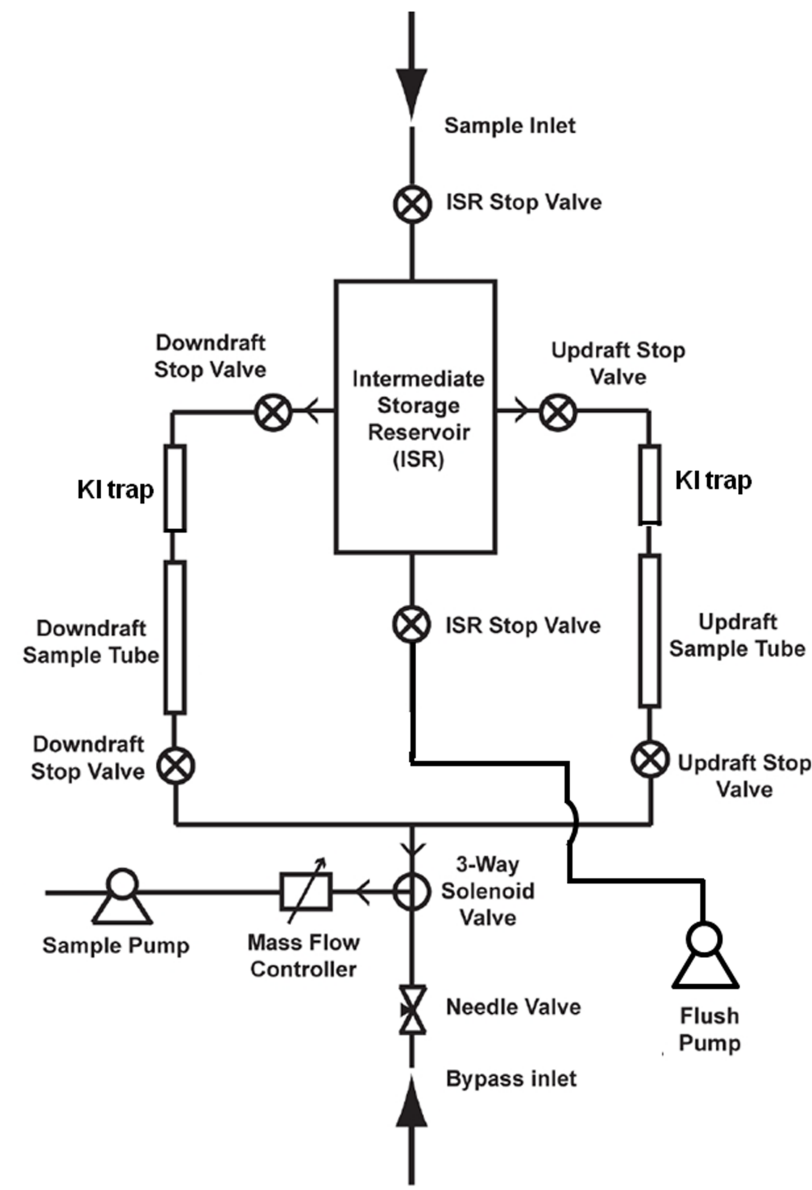

Fig. 1. Schematic diagram of the DEA sampling instrument. The sampler measures $50 \mathrm{~cm} \times 40 \mathrm{~cm} \times 15 \mathrm{~cm}$ and weighs $\sim 50 \mathrm{~kg}$ and is housed in a protective all weather case (Pelican model 1600NF) cooled via computer CPU fans (NMB-MAT \#7015).

Services, Inc.) via a micro diaphragm gas pump (KNF Neuberger, model no. UNMP830) and additional control valves. Each cartridge trap is loaded with $100 \mathrm{mg}$ of Tenax ${ }^{\circledR}$-TA (Scientific Instrument Services, Inc.) to ensure capture of the molecules of interest. The flow rate through the traps was controlled at $200.00( \pm 0.44) \mathrm{sccm}$ using a mass flow controller, MFC (MKS, Inc. 1179A25090). The pressure within the ISR was also monitored using an absolute pressure transducer (Omega; PX181-015G5V). After the sample is acquired, the sampling valves are closed, and the stop valves are opened to re-flush the ISR and repeat the cycle. The cartridge traps accumulate updraft and downdraft samples for user-defined periods of time. Once the cartridges are removed, they are capped at both ends using stainless steel caps with PTFE seals (Scientific Instrument Services, Inc. model 781006), placed in a plastic test tube (BD Falcon 14-959 Series), which itself is purged with high purity nitrogen (UHP 5.0, Praxair). Analyses of the samples were conducted using a commercial thermal desorption system (Scientific Instrument Services TD-4) coupled to a gas chromatograph with a flame ionization detector (HP 5890). Total analysis time between samples, from initial injection to completion of analysis, was $\sim 50 \mathrm{~min}$ per cartridge.

To ensure the cartridges are free from potential interferences prior to sample collection, each sample cartridge is preconditioned. This was achieved by heating the cartridges to $350^{\circ} \mathrm{C}$ for $15 \mathrm{~min}$ under a flow of pure helium (UHP 5.0, Praxair). Sampled cartridges were analyzed after periods of time ranging from $1 \mathrm{~h}$ to 1 week. None of the preconditioned traps showed any artifact peaks in the GCFID chromatograms after the preconditioning process. The finite amount of sorbent materials in the cartridge traps leads to a finite "breakthrough" (or elution) volume (e.g., Simon et al., 1995). Tests were conducted to determine the breakthrough volume for the cartridges used. For the most volatile of the BVOCs of interest, isoprene, the breakthrough volume was found to be in excess of 51 for the cartridges described here. Measurements made using the DEA sampler resulted in sample volumes less than 3.51 (as will be described in Sect. 4). Hence, it is unlikely that any samples were subject to breakthrough. As monoterpenes are less volatile than isoprene, it is likely that the monoterpene breakthrough volume is larger. Similarly, although breakthrough volumes decrease with increasing temperature (Simon et al., 1995), the maximum temperature encountered in the field was only $28^{\circ} \mathrm{C}$ and thus similar to those in the lab experiments (Bertman et al., 2012).

BVOC losses due to reactions in the sample lines of the DEA sampler were assumed to be minimal. During normal operation, the residence time of air samples in the inlet is $0.12 \mathrm{~s}$. BVOCs have lifetimes of several minutes under typical concentrations of atmospheric oxidants $\left(\mathrm{OH}, \mathrm{O}_{3}\right)$ (Atkinson et al., 2006). It is therefore unlikely that the residence time within the inlet line is long enough to cause significant loss of the target molecules prior to trapping within the ISR. Similarly, we assume negligible BVOC loss by $\mathrm{OH}$ during storage in the ISR. OH has an atmospheric lifetime of typically a few tenths of a second at UMBS (DiCarlo et al., 2004), so it is reasonable to assume most(if not all) $\mathrm{OH}$ has been lost prior to reaching the ISR. If some $\mathrm{OH}$ remains, assuming typical ambient concentrations of $\mathrm{OH}$, isoprene and monoterpenes, and a ISR storage time of $20 \mathrm{~s}$, the loss of these molecules due to $\mathrm{OH}$ reaction is less than $1 \%$.

The use of cartridges using Tenax-TA as a sorbent material for measurements of certain BVOC requires significant care (e.g., Helmig, 1997, 1999; Komenda et al., 2001). On the other hand, with adequate quality control, cartridges can be an excellent way to trap these molecules of interest as they offer a convenient way of sample storage and are easy to use. With this in mind, lab tests were undertaken to investigate potential errors, interferences and other issues associated with using sorbent tubes to capture BVOCs. Reactive losses within the ISR are assumed to be small as ozonolysis lifetimes for isoprene are several orders of magnitude longer than for $\mathrm{OH}$ reactions (e.g., Atkinson et al., 2006). BVOCs 
do, however, have the potential to react with ozone while the BVOCs are trapped on the sorbent bed, thereby presenting erroneous results (e.g., Calogirou et al., 1996; Helmig, 1997; Dettmer and Engewald, 2002). This is primarily due to the long accumulation times associated with DEA $(>50$ min for most samples). As summarized by Helmig (1997), various materials can be used to remove ozone during sampling. To allow for maximum recovery of the highly reactive BVOCs, ozone "scrubbers" were added to the DEA sampler immediately prior to the "up" and "down" cartridge traps. These consisted of a $0.635 \mathrm{~cm}$ PFA union loaded with $350 \mathrm{mg}$ of KI. Inert glass wool was used to seal the KI within the ozone scrubber. During laboratory tests, $8 \mathrm{ppb}$ of isoprene and $500 \mathrm{pptv}$ of monoterpenes were sampled onto a cartridge trap every $30 \mathrm{~s}$ for a period of $1 \mathrm{~h}$, first in air with no ozone and then with $50 \mathrm{ppb}$ of ozone added to the samples. No statistically significant loss of BVOCs was observed as a result of the presence of ozone; GC peaks for both isoprene and monoterpenes were within the measured precision indicating effective removal of the ozone by the KI. In addition, the presence of the KI did not cause the formation of any artifacts or additional peaks in the chromatograms or give rise to any change in the flow rate through the cartridge traps. During ambient sampling, each KI scrubber was changed daily. Fick et al. (2001) showed that $200 \mathrm{mg}$ of KI could scrub $75 \mathrm{ppb}$ of ozone without significant artifact formation for $24 \mathrm{~h}$ with over $95 \%$ retention of the BVOC $\alpha$-pinene. Since the sampler does not operate continually, and the ambient air during field deployment contains less than $75 \mathrm{ppb}$ of ozone (Bertman et al., 2012), we assume that the $350 \mathrm{mg} \mathrm{KI}$ scrubbers were able to efficiently remove all ozone during routine operation.

The DEA instrument was calibrated by using gas phase standards made using liquid, reagent grade isoprene, $\alpha$ pinene and $\beta$-pinene (99.9\% purity, Aldrich) and injecting them into a Tedlar ${ }^{\mathrm{TM}}$ bag typically filled with 1201 of air to achieve a known concentration of gas phase BVOCs representative of typical ambient conditions. The relative uncertainty in the mass of species accumulated on a cartridge trap was calculated via Eq. (8), where

$\% e_{\mathrm{conc}}=\sqrt{\left(\% e_{\mathrm{peak}}\right)^{2}+\left(\% e_{\mathrm{cal}}\right)^{2}+\left(\% e_{\mathrm{vol}}\right)^{2}}$.

Here, \%e represents the relative uncertainty and the subscripts "peak", "cal", and "vol" represent the integrated chromatogram peak height, calibration factor (i.e., slope of the calibration curve), and accumulated volume during disjunct sampling. The parameter $\% e_{\text {peak }}$ is affected by precision during desorption, separation, and detection of both isoprene and monoterpenes. Precision was calculated to be $\pm 3 \%(1 \sigma)$ for isoprene and $\pm 8 \%$ for both $\alpha$ - and $\beta$-pinene. The uncertainty of the calibration factor, $\% e_{\text {cal }}$, ranged from $5 \%$ for isoprene to $12 \%$ for $\alpha$-pinene and $\beta$-pinene. The uncertainty in the accumulated volume, $\% e_{\mathrm{vol}}$, was determined to be $4 \%$ (see later). The total propagated relative uncertainty in the masses of species accumulated (\% $\left.e_{\text {conc }}\right)$ was calculated as $9 \%$ for isoprene, $13 \%$ for $\alpha$-pinene and $17 \%$ for $\beta$-pinene.

The uncertainty in the overall flux in any scalar measured by DEA can also be calculated and is given by the propagation of errors in the five individual components that make up Eq. (7). These are the uncertainties in the determined density of scalar in the updraft tube $\left(c^{+}\right)$, the downdraft tube $\left(c^{-}\right)$, the mass of these scalars in the volume collected as updrafts or downdrafts $\left(c_{\mathrm{v}}^{+}\right.$and $\left.c_{\mathrm{v}}^{-}\right)$, the mean vertical wind $\left(\bar{w}_{\text {disj }}\right)$ and mean scalar density $\left(\bar{c}_{\text {disj }}\right)$ of the disjunctly sampled points. Combining Eqs. (7) and (8), we see that this uncertainty, $e_{\text {Flux }}$, is given by

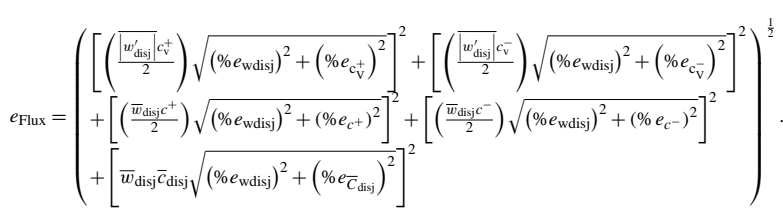

Uncertainties in the flux measurements associated with the solution of Eq. (9) averaged $\pm 35 \%$ for isoprene fluxes and $\pm 56 \%$ for monoterpenes.

\section{Field characterizations}

During summer 2009, the DEA sampler system was mounted at the $26.6 \mathrm{~m}$ level of the walk-up PROPHET tower located at the UMBS site (Carroll et al., 2001). The instrument inlet and sonic anemometer were co-located $2 \mathrm{~m}$ above the sampler, at $28.6 \mathrm{~m}$. As the forest canopy height was, on average, $22.5 \mathrm{~m}$, all measurements represent concentrations and fluxes measured at $6.1 \mathrm{~m}$ above the canopy. Just over a month prior to the start of the CABINEX campaign in July 2009, the sonic anemometer was mounted on the tower, so that representative wind conditions (i.e., a wide range of azimuth angles, wind speeds, and atmospheric stability) could be sampled. The output of the anemometer is relative to the orientation of its three dimensional axes. The wind speed can be transformed into a geographic framework by knowing the cardinal direction in which the anemometer is mounted and assuming the anemometer and the surrounding terrain are level. From data collected in May and June 2009, an apparent correlation between the horizontal wind components and the vertical wind was observed, indicating the measurements were biased by a non-level anemometer, uneven terrain, or other flow disturbances around the tower as noted previously at this site (Martins, 2008).

The effect of "no-level" bias in the sonic anemometer data has been shown to cause errors in the calculated flux (Rinne et al., 2000; Turnipseed et al., 2009). Using these data and based on the recommendations of Turnipseed et al. (2009), an applied $3 \times 3$ matrix was used to virtually rotate the anemometer data into the mean streamline, according to the "planar fit" method (Wilczak et al., 2001). The "planar fit" method uses an ensemble of wind measurements assumed 
to be representative of a broad range of azimuth wind angles, wind speeds, and stability conditions to define a plane. A multiple linear regression is then used to find the best-fit plane that is representative of the mean streamline, and the transformed vertical wind direction $\left(w_{\mathrm{T}}\right)$ is defined perpendicular to this plane. The coordinate rotation algorithm, when applied to the in situ vertical wind data, reduced the correlations such that coupling between the vertical and horizontal wind was removed (correlation coefficient $<0.1$ ).

During this period, the "stationarity" of the location of the DEA sampler was also investigated. As described in the overview by Mahrt (1998), almost all atmospheric towerbased measurements are subject to nonstationary or inhomogeneous conditions to some degree. A practical estimate of the overall flux sampling error owing to inhomogeneous conditions can be constructed in terms of the record of flux between the beginning of the disjunct sampling time and a reference point within the disjunct sample period. Grossman (1992) showed that

$F_{\mathrm{c}}(0, x)=\frac{1}{x_{r}} \sum_{x=0}^{x=x_{r}} w^{\prime} c^{\prime}$

where $x_{r}$ is the $r$-th observational point during sampling and $c$ is any transported scalar. The flux is then repeatedly computed by incrementally increasing $x_{r}$ from some small value up to the length of the entire record to form a time series of $F_{\mathrm{c}}\left(0, x_{r}\right)$. If errors are small, $F_{\mathrm{c}}\left(0, x_{r}\right)$ converges to the record flux well before $x$ approaches the end of that record. Using $10 \mathrm{~Hz}$ sonic anemometer data, sensible heat fluxes were calculated via the eddy covariance (EC) technique described by the solution of Eq. (1). Here, the scalar $c^{\prime}$ in Eq. (1) is replaced by temperature, $T^{\prime}$ (Pressley et al., 2006). Temperatures were calculated from the speed of sound in air data reported by the sonic anemometer. The averaging time was systematically increased from 15 min to the maximum sampling time for a DEA sample, $115 \mathrm{~min}$. The data showed that sensible heat flux does converge quickly. Differences between $F_{\mathrm{c}}$ calculations for sensible heat flux averaged over $115 \mathrm{~min}$ deviated by $<5 \%$ from the averages obtained by averaging over $15 \mathrm{~min}$. Similar trends were observed in the sensible heat data taken during July and early August during the main CABINEX campaign. Although these small differences in $F_{\mathrm{c}}\left(0, x_{r}\right)$ do not rule out significant sampling errors owing to inhomogeneity at the instrument sampling height, these appear to be smaller than the uncertainty propagated via the solution of Eq. (9).

As described by Turnipseed et al. (2009), the selection of the maximum wind speed expected during a disjunct sampling period, $w_{\max }$, can be used to determine the maximum rate at which the cartridge traps are filled. Underestimation of $w_{\max }$ can lead to the dispense cycle being terminated prematurely, thereby causing some sample volume to be "missed". If $w_{\max }$ is set too large, only small sample volumes and, thus, scalar densities are collected. This may make determination of BVOC concentrations less reliable. During CABINEX, $w_{\max }$ was set according to the maximum predicted vertical wind speed for that hour, which was chosen to be $3 \sigma$ of the vertical wind speeds measured during the previous hour. This calculation is performed automatically by the sampling computer which then adjusts the maximum sampling time as turbulent eddies vary during the day. If $w_{\text {disj }}>w_{\max }$, the DEA sampler cartridges were filled for a default period of $20 \mathrm{~s}$ (the maximum sample time available).

Similarly, $w_{\text {min }}$ (the minimum vertical wind determined to be an actual eddy) was also determined. The use and impact of this dead-band threshold in REA measurements have been well documented (e.g., Oncley et al., 1993; Bowling et al., 1999; Ammann and Meixner, 2002; Ren et al., 2011), but the application has not been applied to the few DEA measurements so far reported (Rinne et al., 2000, 2002; Turnipseed et al., 2009). Since our sampler therefore differs from the methodologies described to date, we must then assess the impact on the calculated fluxes. For example, if $w_{\min }$ is too conservative, this could lead to sampling of sonic anemometer noise and collection of disjunct samples that are not truly representative of the turbulent flux. If $w_{\min }$ is too large, small eddies typically observed during calm periods (e.g., early morning or late afternoon) could be "missed". Bowling et al. (1999) showed that, for an REA sampler, using a deadband threshold that was allowed to change between sampling periods, but remained constant over that period, could significantly improve capture of flux. The authors concluded that using this "moving threshold" provided good estimates of flux obtained via REA when compared to EC flux measurements. Consequently, a threshold of $2 \sigma / 3(0.66 \sigma)$ was found for the previous hour's vertical wind for the data described here.

The reasons for using this value were twofold. The discontinuous nature of DEA allows for traceable mass flow control for each sample as it is taken, and precise knowledge of the sample volume for the scalar being examined is necessary. However, errors can be introduced into the determination of scalar density based on the ability of the MFC to deliver precise target volumes, especially over short sample times. Experiments were performed by manually varying the sample time at a constant flow rate of $200.00 \mathrm{sccm}$ and comparing the actual (integrated flow rate) volume to the target (calculated) volume as a function of sample time. The results are shown in Fig. 2. Figure 2 shows that when the ISR valves are opened, deviations in the flow rate are initially observed due to changes in pressure upstream of the MFC. This error is only of concern at short dispense times, i.e., small $w_{\text {disj val- }}$ ues, and the flow rate returns to the set point within ca. $3 \mathrm{~s}$. Thus, at longer dispense times (i.e., larger $w_{\text {disj }}$ values), the uncertainty in the flow is integrated away and delivery volume evens out to be within $4 \%$ of the target. The sample time threshold (which can be converted to minimum wind speed threshold) can then be defined as the time when this relative error becomes adequately small. 


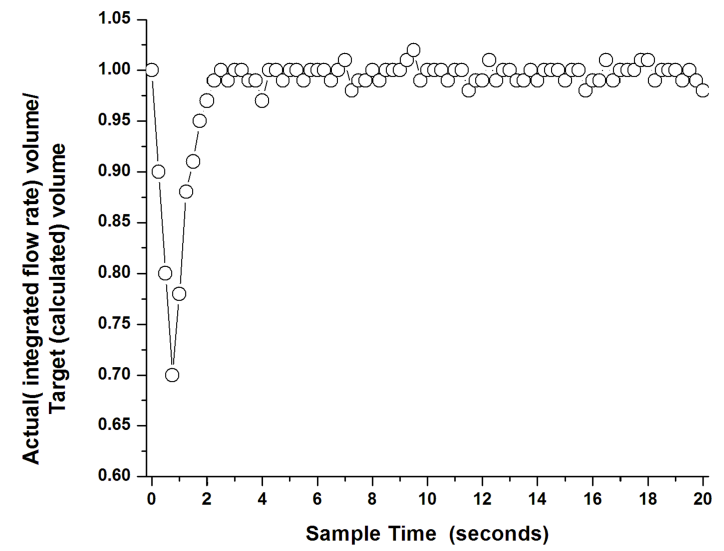

Fig. 2. Effect of pressure spikes upon opening the ISR sample valves on the ratio of actual flow rate/target flow rate. To eliminate these pressure spikes, values of $w$ corresponding to sample times $>3.0 \mathrm{~s}$ were not sampled. This conservative estimate resulted in the inclusion of a dead-band threshold in the DEA measurements, but such a threshold has negligible effect on sample volumes accumulated or calculated flux (see text for details).

To ensure that no pressure transients were likely to impact the determined volume, a conservative threshold that eliminated all sample times of $\leq 3.0 \mathrm{~s}$ was used in CABINEX. To examine how this sample time translated into a detected vertical wind, the 34 days of vertical wind data taken prior to the start of the CABINEX campaign were examined. It was found, on average, DEA cycles with dispense times $\leq 3.0 \mathrm{~s}$ occurred infrequently ( $\leq 10 \%$ on the time) if $w_{\min }$ was set to $0.66 \sigma$ of the previous hour's average vertical wind. If $w_{\text {disj }}$ was lower than this value, the vertical wind was still recorded by the computer software but the computer did not open the valves to sample the corresponding eddy and it did not contribute to the accumulated sample volume. Using these thresholds, the DEA sampler acquired over 6000 samples in the CABINEX campaign. $44.2 \%$ of the samples were detected as updrafts and $43.6 \%$ were downdrafts. For the remaining $12.2 \%$ of the samples, the vertical wind was below the $w_{\min }$ threshold. Recorded winds larger than $w_{\max }$ took place infrequently, and this "undersampling" occurred in only $2.5 \%$ of the samples taken during CABINEX. The delivered volume to each cartridge ranged from $112 \mathrm{~cm}^{3}$ to $3159 \mathrm{~cm}^{3}$ with a mean sample volume of $1245 \mathrm{~cm}^{3}$.

Using these thresholds does lead to the potential for accumulated sample volumes significantly different than those that would be accumulated if all eddies were sampled. Although the times where $w_{\text {disj }}<w_{\min }$ were infrequent, the small eddies associated with these small vertical winds are still part of the flux. By not sampling them, the difference between the updraft scalar and the downdraft scalar $(\Delta \mathrm{C})$ could be artificially large (Pattey et al., 1993). In REA instruments, this is compensated for by adjusting a dimensionless, empirical coefficient $\beta$ used to calculate REA flux.
Usually, this is achieved by conditionally sampling at $10 \mathrm{~Hz}$ wind/temperature data to derive the $\beta$ coefficient with the same threshold used as when sampling/accumulating at valve speeds < $10 \mathrm{~Hz}$ (e.g., Bowling et al., 1999; Ammann and Meixner, 2002). In true DEA sampling, no such empirical correction coefficients are used in the calculation of DEA flux, but, by using a dead-band approach for data all recorded using our sampler, a smaller factor is needed.

To find the magnitude of this correction, $10 \mathrm{~Hz}$ sonic anemometer wind/temperature data were analyzed with simulated DEA sampling. This enabled both estimations of the effect of the dead-band on $\Delta \mathrm{C}$ and also, whether using a dead-band creates the need for an empirical correction in the DEA flux (A. Turnipseed, personal communication, 2012). First, data were considered where all eddies were used to calculate the simulated accumulation volumes. These data were then compared to cases where $w_{\min }$ thresholds of $0.25 \sigma$, $0.33 \sigma, 0.50 \sigma, 0.66 \sigma, 1 \sigma$ and $1.50 \sigma$ were applied to the data, thus eliminating smaller eddies from the calculation. Comparing these simulations, using a threshold value $w_{\min }$ does lead to a larger concentration difference between the updraft and downdraft reservoirs $(\Delta \mathrm{C})$, but the difference is small relative to the size of the total sample volume. This is similar to the findings of Bowling et al. (1999). For example, using the threshold of $0.25 \sigma$, the simulated total volume differed by $2.3 \%$ while the difference was $26.2 \%$ when threshold was set to $1.50 \sigma$. For the threshold of $0.66 \sigma$ used in CABINEX, the total volumes differed by $11.1 \%$.

Simulated fluxes were also determined for the various thresholds. As the sonic anemometer reports the vertical wind even when no sample is taken $\left(w_{\text {disj }}<w_{\text {min }}\right)$, the effect on flux can be calculated for cases, where all $w$ values are included or where some values of $w$ are rejected (assuming delivery by the MFC of a consistent target volume for the shortest sampling times). Here, $10 \mathrm{~Hz}$ sonic anemometer data were used to simulate disjunct sampling/accumulation of sonic anemometer wind/temperature data to compute the change in sensible heat flux for cases where the small eddies are both included in the calculation and then, are eliminated by application of the various dead-bands. The data comparison again shows that only small corrections are necessary for most thresholds. The flux difference ranged from $1.9 \%$ where $w_{\min }=0.25 \sigma$, to $23.2 \%$ for a $1.50 \sigma$ threshold. The $0.66 \sigma$ threshold used in CABINEX saw a difference of $8.6 \%$; that is, the net effect of using the $0.66 \sigma$ threshold is to overestimate (true) DEA flux by $8.6 \%$ owing to this systematic bias. This correction factor is effectively a constant and thus can be corrected for through the broad application to all flux data calculated during CABINEX.

\section{Isoprene concentrations and fluxes during CABINEX}

Due to limitations on the number of sample cartridges, daily continuous DEA measurement was not possible. Instead, the 

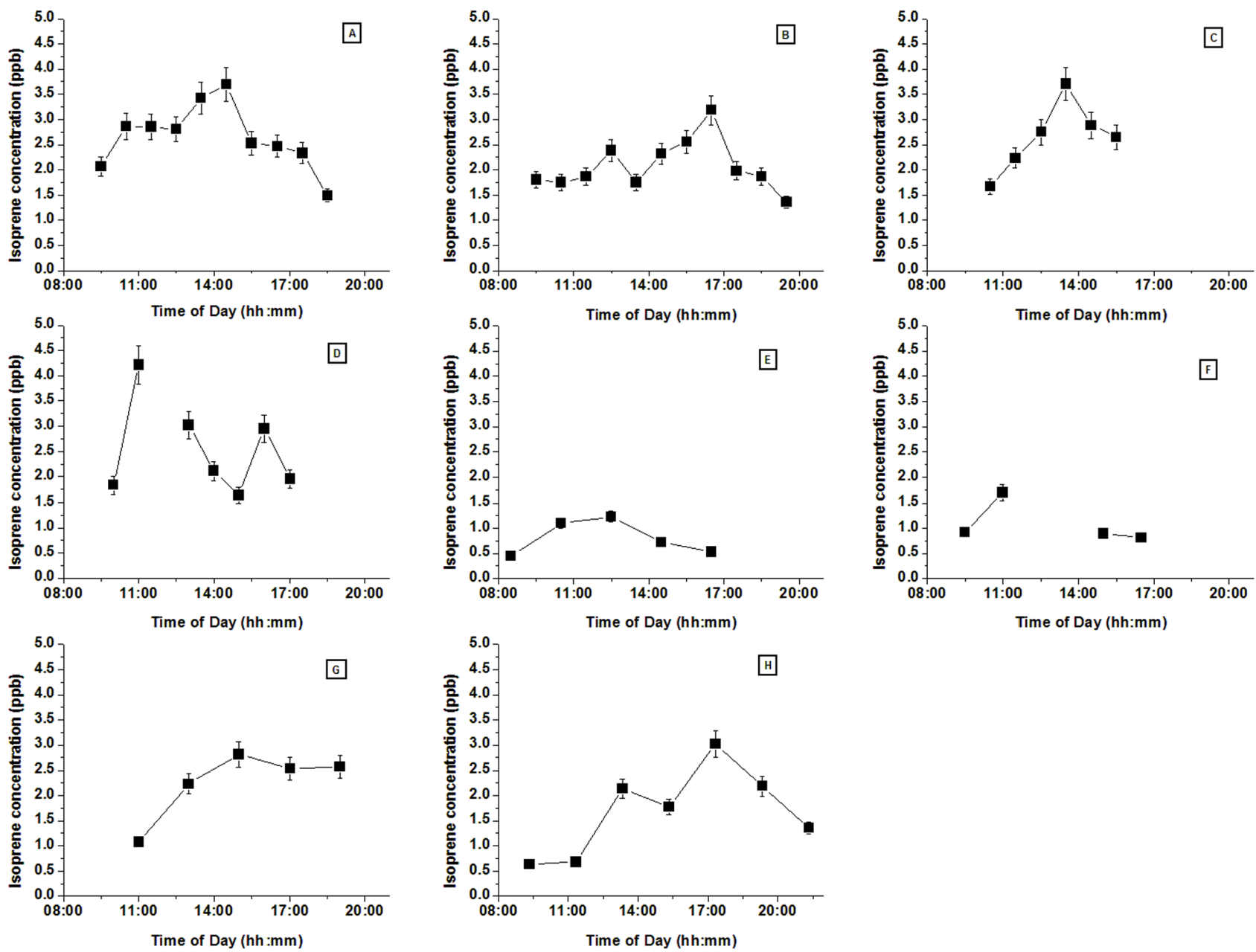

Fig. 3. Isoprene concentrations (in ppbv) measured during the 2009 CABINEX campaign via DEA. Data show daily isoprene concentrations during the eight intensives the DEA was deployed. Letters assigned to plots in Fig. 3 and all subsequent figures represent the days of measurement: A =9 July, B=14 July, C=20 July, D = 21 July, E=26 July, F=30 July, G=31 July, H=4 August. Each data point represents the midpoint of the averaging period, which ranged from 55 to $115 \mathrm{~min}$. Error bars represent the propagated uncertainty in the derived concentration (see text for details).

campaign was broken up into eight DEA sampling "intensives", conducted between 9 July and 4 August 2009, with gaps of several days in between to allow for sample analysis and regeneration of the cartridge traps. Prior to beginning each intensive, the DEA sampler was calibrated and blank samples were acquired. Calibrations performed in the field showed little difference in GC-FID sensitivity and little to day-to-day variation between slopes of calibration curves observed. During CABINEX the instrument had a calculated limit of detection of $15 \mathrm{pptv}$ with an instrument precision of $3 \%$. Each cartridge was analyzed within four days of collection.

Figure 3 shows the isoprene concentrations measured during each day of the CABINEX intensives where the sorbent cartridges could be analyzed successfully. Some data are missing owing to tube leaks or other problems during sample collection. From these available data, isoprene has a distinct diurnal profile, with isoprene concentrations rising to a maximum in the midafternoon, as previously observed by several authors (Edwards et al., 2007; Apel et al., 2001; Westberg et al., 2001). The mean, midday (10:00-14:00 LT - local time) isoprene concentration was $2.1( \pm 0.2) \mathrm{ppb}$. These data compare to median isoprene concentrations of $2.0( \pm 0.4) \mathrm{ppb}$ reported during the PROPHET 1998 experiment at this site (Apel et al., 2001). The maximum observed isoprene concentration was $4.22 \mathrm{ppbv}$, with a minimum value of $0.45 \mathrm{ppbv}$, although no isoprene measurements were taken at night when isoprene concentrations are typically much lower (e.g., Edwards et al., 2007). Also shown in Fig. 3 are $1 \sigma$ uncertainties associated with each calculated isoprene value following the solution of Eq. (8). As described above this was determined to be $9 \%$ for isoprene. Figure 4 shows the corresponding isoprene fluxes and associated uncertainties for each of the intensives. Data show a distinct diurnal profile with a positive, 

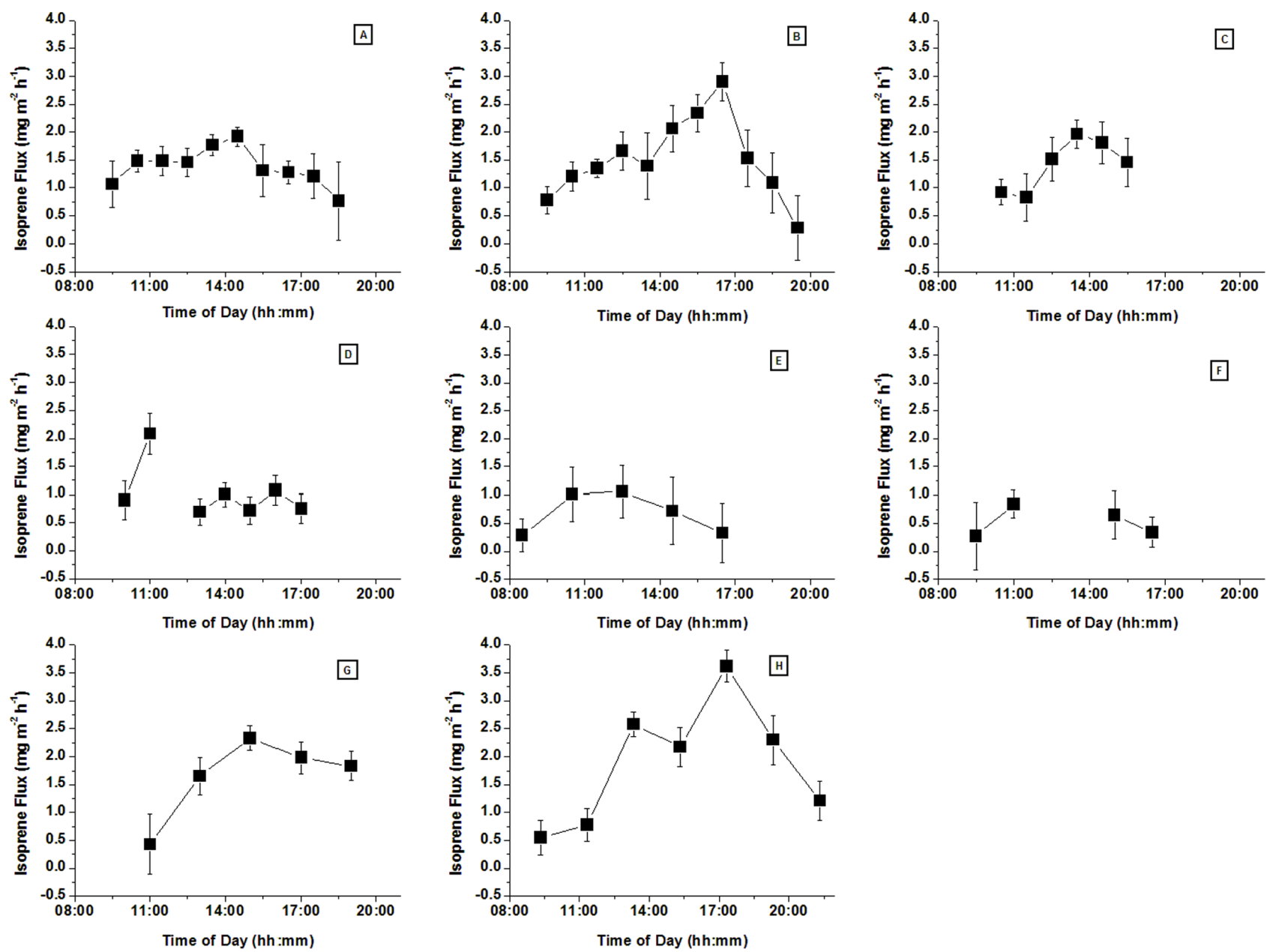

Fig. 4. Isoprene fluxes $\left(\mathrm{mg} \mathrm{m}^{-2} \mathrm{~h}^{-1}\right)$ measured during the CABINEX 2009 campaign via DEA during the same eight intensives. Again, data represent time averages flux over the DEA measurement cycle and the tower footprint. Error bars represented the propagated uncertainty associated with each flux measurement data point.

or net upward flux observed in all data. Fluxes are low during the early morning before a steady increase. Isoprene fluxes are at a maximum in the midafternoon. he maximum observed isoprene flux was $3.62 \mathrm{mg} \mathrm{m}^{-2} \mathrm{~h}^{-1}$, with a minimum value of $0.27 \mathrm{mg} \mathrm{m}^{-2} \mathrm{~h}^{-1}$. The median isoprene flux was $1.31 \mathrm{mg} \mathrm{m}^{-2} \mathrm{~h}^{-1}$. These values are within the range of daytime measurements of $1.0 \mathrm{mg} \mathrm{m}^{-2} \mathrm{~h}^{-1}$ to $12.0 \mathrm{mg} \mathrm{m}^{-2} \mathrm{~h}^{-1}$ previously reported at this site (Westberg et al., 2001). The propagated uncertainty in the DEA isoprene flux was, on average, $\pm 35 \%$. The largest uncertainty determined in these data was $\pm 70 \%$, and the minimum was $\pm 16 \%$. Uncertainties were typically larger during times when isoprene concentrations were small, e.g., during the early morning or late afternoon.

\section{Comparison to sensible heat flux, $H$}

Although the magnitude of the correlation between isoprene fluxes and energy fluxes varies from one day to the next, Pressley et al. (2006) showed that longer-term averages suggest strong linear correlations between isoprene fluxes and energy fluxes at this site. These correlations were also observed by Rinne et al. (2002) during DEA measurements of BVOC fluxes in the Amazon. Similarly, it has been shown by Westberg et al. (2001) that the diurnal pattern of $H$ is almost identical to the diurnal pattern of isoprene flux. This is due to the biosphere-atmosphere exchange of energy being driven by environmental parameters that also drive isoprene emissions (temperature and solar radiation). Likewise, canopy dynamics also affect both energy and isoprene exchange. Sensible heat fluxes were calculated and averaged to the same time period as DEA isoprene flux measurements allowing direct comparison between these two variables. Linear regression of isoprene fluxes vs. $H$ for the whole campaign 


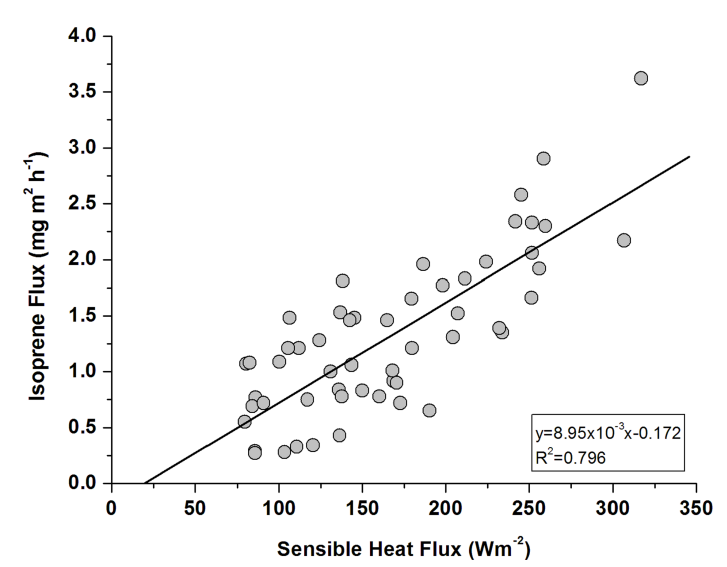

Fig. 5. Averaged isoprene fluxes for the whole CABINEX 2009 campaign versus the corresponding average sensible heat flux $\left(\mathrm{W} \mathrm{m}^{-2}\right)$ derived from eddy covariance of sonic anemometer temperature data, averaged to DEA measurement times.

is shown in Fig. 5. These data show slope of $8.95 \times 10^{-3}$, with an $R^{2}$ of 0.796 during CABINEX, compared to Presley et al. (2006), who reported an average slope of $1.32 \times 10^{-2}$ $\left( \pm 5.93 \times 10^{-3}, R^{2}=0.884\right)$. A close correlation between these data suggests that, over a wide range of ambient conditions during CABINEX, the DEA instrument was able to capture the major environmental parameters that drive isoprene emissions and exchange between the canopy and the atmosphere.

\section{Comparison to isoprene emission models}

Guenther et al. (1991, 1993) showed that isoprene emission can be quantified via

$I=I_{S} \times C_{L} \times C_{T}$.

Here, $I$ is the isoprene emission rate at ambient temperature $(T)$ and photosynthetically active radiation flux (PAR). $I_{S}$ is the base emission rate (grams carbon as isoprene per gram dry leaf mass per hour) at a standard temperature of $30^{\circ} \mathrm{C}$ and PAR flux of $1000 \mathrm{~mol} \mathrm{~m}^{-2} \mathrm{~s}^{-1}$. In this study, an $I_{S}$ value of $70 \mu \mathrm{g} \mathrm{Cg}^{-1} \mathrm{~h}^{-1}$ was used (Guenther et al., 1995). The parameters $C_{L}$ and $C_{T}$ are environmental adjustment functions for PAR and temperature, respectively. The factor $C_{L}$ is a function of the PAR flux and is defined as

$$
C_{L}=\frac{\alpha C_{L 1} \mathrm{PAR}}{\sqrt{1+\alpha^{2} \mathrm{PAR}^{2}}} .
$$

The values $\alpha=0.0027$ and $C_{L 1}=1.066$ are empirical constants derived by Guenther et al. (1993) by fitting the above expression to measured emission rates. The temperature dependence of isoprene emissions is controlled by the factor $C_{T}$, which is defined in Eq. (12) and has been used to describe the temperature response of enzymatic activity (Guenther et al., 1993).

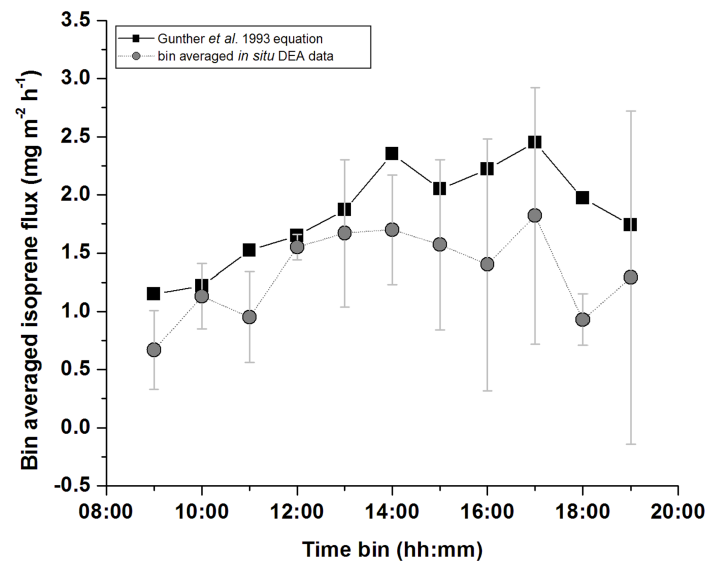

Fig. 6. Comparison of average isoprene flux measured by DEA during CABINEX 2009 to emission algorithms described by Guenther et al. (1993). The emission algorithm overpredicts measured isoprene fluxes but is generally within the $1 \sigma$ standard deviation of the isoprene flux as shown.

$C_{T}=\frac{\exp \frac{C_{T 1}\left(T-T_{\mathrm{s}}\right)}{R T_{\mathrm{s}} T}}{1+\exp \frac{C_{T 2}\left(T-T_{m}\right)}{R T_{\mathrm{s}} T}}$.

Here, $T$ is the leaf temperature, $R$ is the ideal gas constant $\left(8.31 \mathrm{~J} \mathrm{~mol}^{-1} \mathrm{~K}^{-1}\right), C_{T 1}=95 \mathrm{~kJ} \mathrm{~mol}^{-1}, C_{T 2}=230 \mathrm{~kJ} \mathrm{~mol}^{-1}$, and $T_{m}=314 \mathrm{~K}$; the values of these coefficients were determined by Guenther et al. (1993) by fitting to experimental data. $T_{\mathrm{S}}$ is a standard temperature, $303 \mathrm{~K}$. Data for PAR were obtained from in situ measurements made by the University of Houston (B. Lefer, personal communication, 2011), while temperature data were also recorded as part of the meteorological dataset (Bertman et al., 2012). These data were averaged to the same time base as the DEA data $(55 \mathrm{~min})$ and represent the midpoint of that averaging period. Comparison of the estimated isoprene flux via this algorithm and the isoprene flux measured by DEA is shown in Fig. 6. The data suggest that the measured DEA isoprene flux is comparable to the algorithms described by Guenther et al. (1993) both in profile and peak flux. Although the emission algorithm does overpredict the averaged flux by $27 \%$, this overprediction is within the $1 \sigma$ uncertainty of the measured data and could also be due to other factors (e.g., canopy shading) that were not accounted for.

\section{Monoterpene concentrations and fluxes during CABINEX}

Concentrations and fluxes of the individual monoterpenes $\alpha$ pinene and $\beta$-pinene were also measured using DEA during the CABINEX campaign. There were six intensives for which there were measurable concentrations of these species, as shown in Fig. 7. Unlike isoprene, no definitive diurnal 

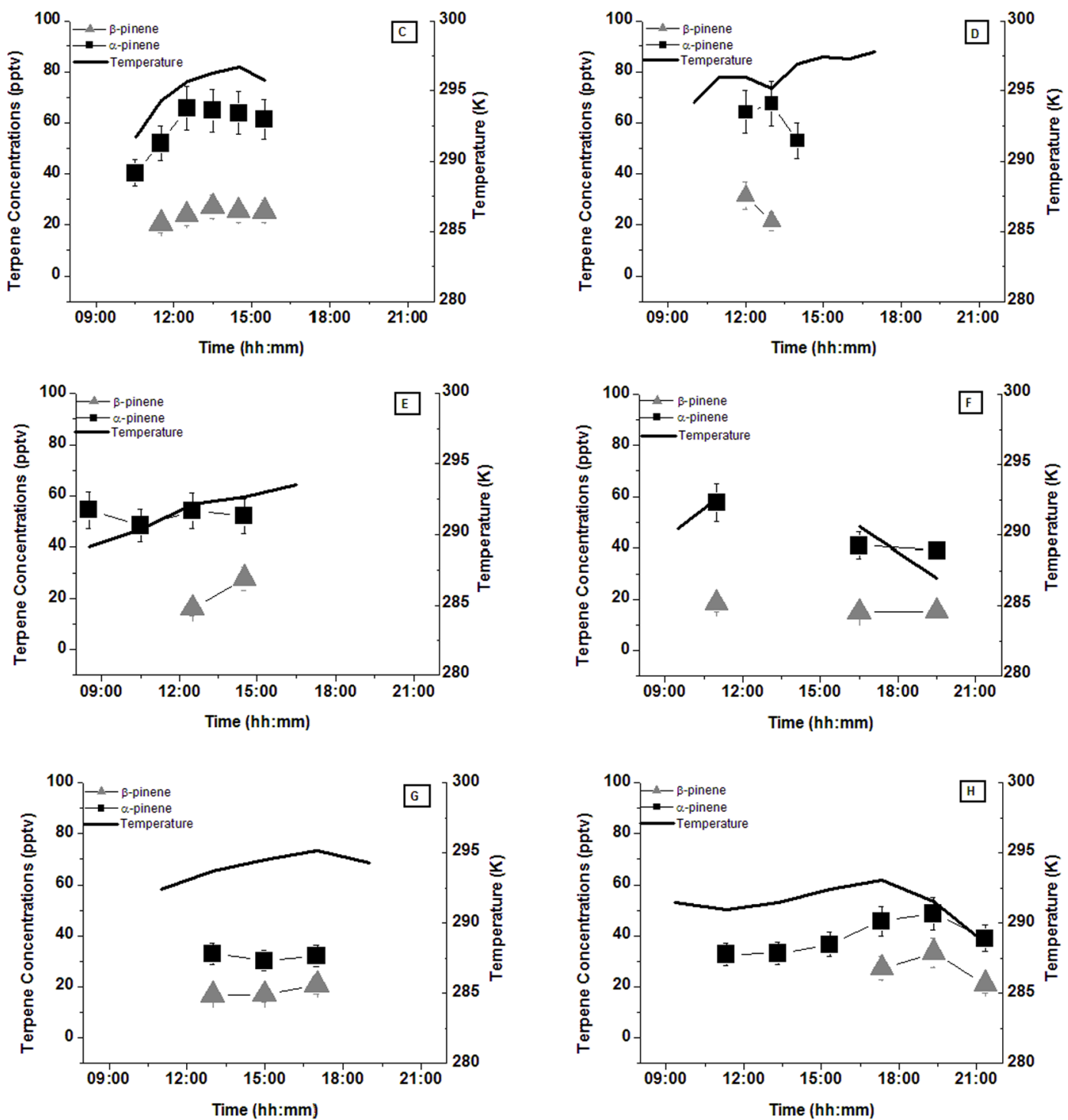

Fig. 7. Concentrations of $\alpha$ - and $\beta$-pinene measured via DEA during six intensives of the CABINEX 2009 campaign. Data show very low concentrations owing to the nature of this forest site as the forest is dominated by isoprene-emitting trees rather than terpene-emitting species. Error bars represent the propagated uncertainty associated with the monoterpene measurements. The secondary axis represents change in ambient temperature over the course of the day.

profile was observed during the daytime sampling, and concentrations were several orders of magnitude smaller than for isoprene. In order to capture the low concentrations of monoterpenes at this field site that is dominated by isopreneemitting trees, it was necessary to extend the DEA sampling period to $115 \mathrm{~min}$. Almost no monoterpenes data were able to be quantified during the first few CABINEX intensives, in which the sampling times were typically $55 \mathrm{~min}$. This accumulation period was insufficient to preconcentrate enough monoterpenes to be statistically significantly different from the blank chromatogram. In addition, no other monoterpene species were successfully quantified in this campaign as the concentrations of these species were either not significantly different from blanks or no primary monoterpene standards were available for calibration. For these longer sampling time periods, $\alpha$-pinene was always above the detection limit ( 15 pptv), whereas in only 18 of the 25 samples $\beta$-pinene showed concentrations above the detection limit. Hence, in Fig. 7, for some of the measurement periods, we report concentrations of $\alpha$-pinene but not the corresponding concentration of $\beta$-pinene. The concentrations observed during CABINEX ranged from a maximum of $67.4( \pm 8.8) \mathrm{pptv}$ for $\alpha$-pinene and $33.3( \pm 5.7)$ pptv for $\beta$-pinene to a minimum of $30.2 \mathrm{pptv}$ for $\alpha$-pinene and $15.3( \pm 3.5) \mathrm{pptv}$ for $\beta$ pinene. Median concentrations were $48.6( \pm 6.8) \mathrm{pptv}$ and $27.2( \pm 7.2)$ pptv for $\alpha$ - and $\beta$-pinene, respectively. 
For UMBS, Kim et al. (2009) previously reported concentrations of total mono- and sesquiterpenes using data taken via PTR-MS during summer 2005. Data showed an average total monoterpene concentration of $\sim 200 \mathrm{pptv}$. Similarly, an average total monoterpene concentration of $\sim 170 \mathrm{pptv}$ was reported during the summer 2008 PROPHET study by Mielke et al. (2010) using a proton transfer reaction linear ion trap mass spectrometer. Speciated monoterpene measurements at this field site have been infrequently reported in the literature. Branch enclosure measurements made by Ortega et al. (2007) showed that the dominant light-dependent monoterpene emitted from all deciduous species was transocimene with conifers emitting $\alpha$-pinene, $\beta$-pinene, camphene, d-limonene, and para-cymene, among other monoterpenes. Kim et al. (2009) reported speciated monoterpenes from canister measurements taken in their 2005 study. The monoterpene budget was determined to be made up of primarily $\alpha$ - and $\beta$-pinene (33\% and $28 \%$, respectively) with average concentrations of these monoterpenes being reported as $60 \mathrm{pptv}$ for $\alpha$-pinene and $50 \mathrm{pptv}$ for $\beta$-pinene. All of these literature data are in close agreement, if slightly larger than those measured by DEA in the 2009 CABINEX campaign. The control of monoterpene emissions at this site seems to be strongly linked with temperature, as predicted by Guenther et al. (1993). Also shown in Fig. 7 is the temperature profile over the disjunct accumulation time of $115 \mathrm{~min}$. Ambient temperatures during CABINEX were significantly lower than those previously recorded at UMBS (Bertman et al., 2012), and often temperature data showed little diurnal variation.

Figure 8 shows $\alpha$ - and $\beta$-pinene fluxes at the CABINEX site as well as temperature data associated with these fluxes included for reference. As described previously, for some cartridges it was not possible to distinguish the $\beta$ pinene peak, hence the absence of these data for times where $\alpha$-pinene fluxes are reported. From Fig. 8, the speciated monoterpene flux shows that $\alpha$-pinene fluxes were slightly greater than those of $\beta$-pinene. The maximum observed $\alpha$-pinene flux was $64.9 \mu \mathrm{g} \mathrm{m}^{-2} \mathrm{~h}^{-1}$, with a minimum value of $10.2 \mu \mathrm{g} \mathrm{m}^{-2} \mathrm{~h}^{-1}$. The median $\alpha$-pinene flux was $26.7 \mu \mathrm{g} \mathrm{m}^{-2} \mathrm{~h}^{-1}$. For $\beta$-pinene, maximum, minimum, and median fluxes were $21.8,6.4$, and $10.6 \mu \mathrm{g} \mathrm{m}^{-2} \mathrm{~h}^{-1}$, respectively. Figure 8 also shows the propagated uncertainty in the determined monoterpene flux. These uncertainties are much larger than for isoprene due to the very low concentrations of monoterpenes measured during the campaign, combined with larger precision for the monoterpenes. The propagated uncertainty in the DEA terpene flux was, on average, $\pm 56 \%$. The largest uncertainty determined in these data was $\pm 91 \%$, while the minimum was $\pm 20 \%$.

Ratios of $\alpha$-pinene and $\beta$-pinene fluxes to isoprene flux were calculated. The data show that daytime fluxes of these monoterpenes were $\sim 20-50$ times less than those of isoprene, with almost no diurnal trend observed. Kim et al. (2009) reported the average daytime ratio between $\alpha$-pinene $+\beta$-pinene flux and isoprene fluxes was $5.1 \%$. This compares favorably to the value calculated by Ortega et al. (2007) of $4 \%$ based on branch enclosure measurements. Using the DEA data measured during CABINEX, this ratio was slightly lower than previously reported and was calculated as $2.8 \%$, although the uncertainty associated with the ratio is large $( \pm 6 \%)$ and thus care needs to be used in the direct comparison of the data presented here with these previous measurements.

\section{Comparison to 1-D atmospheric chemistry model}

For comparison with the $\alpha$-pinene and $\beta$-pinene concentrations and fluxes measured during CABINEX, a simplified atmospheric chemistry one-dimensional model was utilized to simulate the emission, vertical transport, and reaction of 57 BVOCs identified by branch-level speciated emission rate measurements at the UMBS site (Pratt et al., 2012). Detailed descriptions of BVOC emissions, vertical transport, chemical reactions, and horizontal advection are included in Pratt et al. (2012). Briefly, the model consists of 25 vertically spaced bins, including 2 bins within the forest canopy, from $12 \mathrm{~m}$ above the surface to approximately $4 \mathrm{~km}$. Herein, we concentrate on the above-calculated canopy fluxes and concentrations of $\alpha$-pinene and $\beta$-pinene on two mostly sunny days: 21 July and 4 August 2009.

As discussed above, monoterpene emissions are primarily driven by temperature, which can be parameterized by a $\beta$ factor, measured for the different tree species at UMBS during branch-enclosure experiments; therefore, the emission rates of $\alpha$-pinene and $\beta$-pinene were calculated according to Guenther et al. (1993):

$\operatorname{ER}(T)=\operatorname{ER}\left(T_{\mathrm{s}}\right) \times \exp \beta\left(T-T_{\mathrm{S}}\right)$.

$\operatorname{ER}\left(T_{\mathrm{S}}\right)$ is the BVOC emission rate at a standard temperature of $303.15 \mathrm{~K}$, and $T$ is 30 -min resolution average measured temperature at $26.6 \mathrm{~m}$ for the two chosen days. Previous measurements of monoterpene $\beta$-factors showed an average value of $0.14 \mathrm{~K}^{-1}$ with inner-quartile ranges of 0.11 $0.17 \mathrm{~K}^{-1}$ (Ortega et al., 2008). In addition, monoterpene emissions have been observed to vary considerably between individual trees at UMBS (Ortega et al., 2008), similar to previous observations elsewhere by Guenther et al. (1991). Therefore, three emissions scenarios were constructed to examine the model sensitivity to BVOC emissions. For the base case, monoterpene emission rates were calculated using the average $\beta$-factor $\left(0.14 \mathrm{~K}^{-1}\right)$, as well as scaling by $+107 \%$; Ortega et al. $(2007,2008)$ previously reported a measurement uncertainty of $27 \%$, as well as sampling losses ranging from $10-80 \%$. The maximum emission scenario utilized the lower-quartile $\beta$-factor $\left(0.11 \mathrm{~K}^{-1}\right)$ with a scaling by $+107 \%$; correspondingly, the minimum emission scenario used the upper-quartile $\beta$-factor $\left(0.17 \mathrm{~K}^{-1}\right)$ with a scaling by $+10 \%$. Pratt et al. (2012) found the base emission scenario 

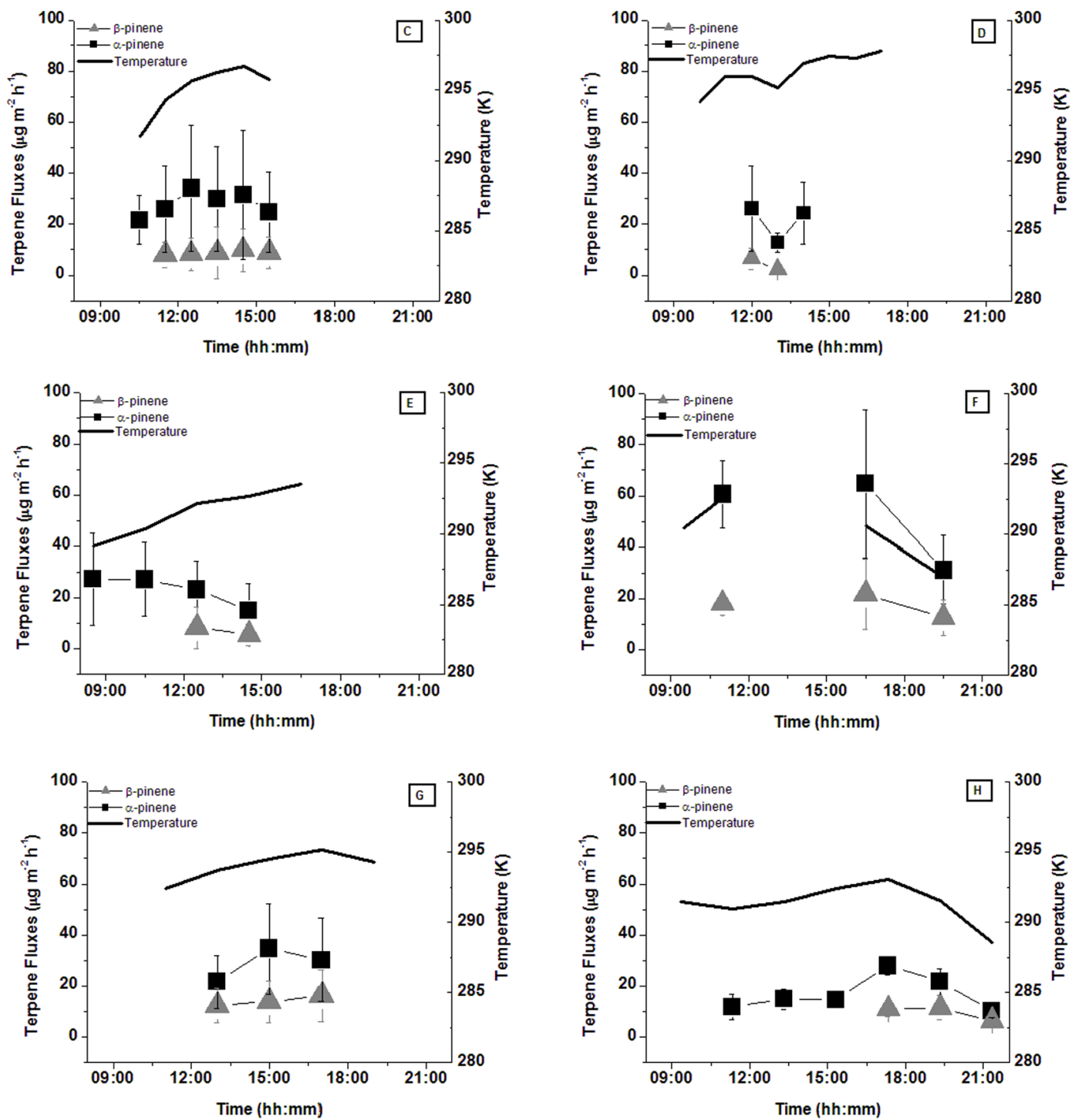

Fig. 8. $\alpha$-pinene and $\beta$-pinene fluxes measured by DEA during six intensives during CABINEX 2009. Error bars represent the propagated uncertainty associated with each flux measurement data point. The secondary axis represents change in ambient temperature over the course of the day.

to produce agreement with the measured total concentration of monoterpenes in the daytime at $\sim 12 \mathrm{~m}$ above the forest canopy.

Within the model, $\alpha$-pinene and $\beta$-pinene reacted with $\mathrm{OH}, \mathrm{O}_{3}$, and $\mathrm{NO}_{3}$ according to literature rate constants (Atkinson et al., 2006). Half-hour average measured diurnal cycles of $\mathrm{OH}, \mathrm{O}_{3}$, and $\mathrm{NO}_{3}$ were utilized as inputs for oxidant concentrations. Above canopy ( $32 \mathrm{~m}$ above ground), $\mathrm{OH}$ concentrations were measured by laser-induced fluorescence (Dusanter et al., 2009). $\mathrm{O}_{3}$ was measured at $32 \mathrm{~m}$ using a Thermo Environmental Instruments model 49C UV absorption ozone analyzer (M. Carroll, personal communication, 2011). $\mathrm{NO}_{3}$ radical concentrations were calculated using a simple box model, based on that described elsewhere (Hurst et al., 2001; Pratt et al., 2012).

$\alpha$-pinene and $\beta$-pinene concentrations and fluxes measured by DEA were compared to model outputs for the sampling height for the two days in question. The comparisons of monoterpene concentrations are shown in Fig. 9, while Fig. 10 shows the comparison of measured fluxes and emission data. The model error bars are large owing to the large propagated variability and uncertainty in the emission rates, showing the need for speciated flux measurements to reduce the uncertainties and further understand the associated chemistry. However, when also taking into account the propagated uncertainties in these measured data (not shown to maintain clarity), the measured data points are within the propagated 

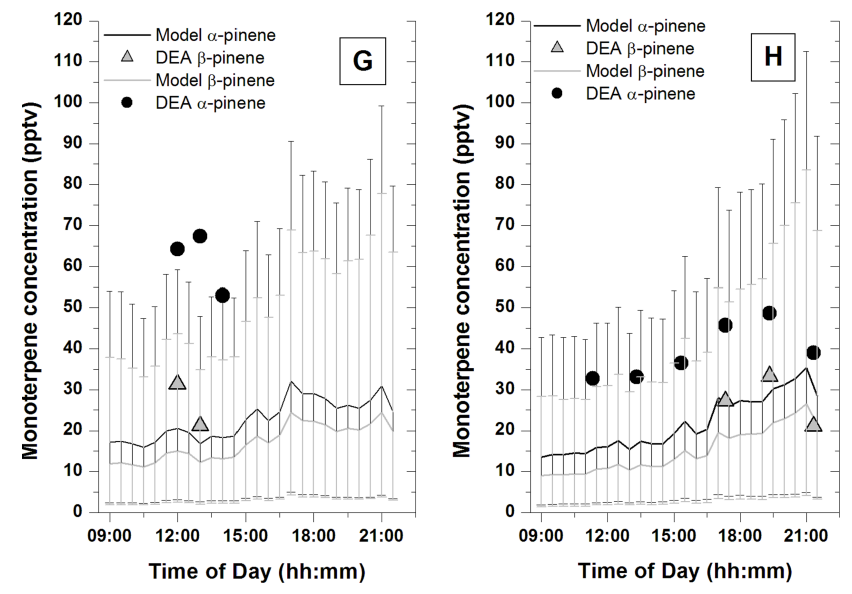

Fig. 9. Comparison of $\alpha$-pinene and $\beta$-pinene concentrations to a 1$\mathrm{D}$ atmospheric chemistry model. Using data measured during CABINEX 2009 to constrain the model, calculated concentrations of $\alpha$ and $\beta$-pinene compare well with the DEA measurements on two partly sunny days tested 21 July (panel D) and 4 August (panel $\mathbf{H}$ ), despite the inherently low terpene concentrations at this field site.

uncertainties associated with the model results. This suggests that the emission rates used to parameterize the model are reasonable, and the measured data obtained by DEA are representative of the monoterpene fluxes at this site. During the 21 July comparison, averaged model $\alpha$-pinene concentrations were $26.0 \mathrm{pptv}$ during daylight hours, compared to a measured average of $61.5 \mathrm{pptv}$ ( $\pm 8 \mathrm{pptv})$. Similarly for $\beta$ pinene, the model averaged 19.7 pptv compared to a measured concentration of $26.3 \mathrm{ptvv}$ ( $\pm 4.5 \mathrm{pptv}$ ) at the site. For data calculated on 4 August, average model $\alpha$-pinene concentrations were $18.2 \mathrm{pptv}$ compared to the DEA measured value of $39.3 \mathrm{pptv}( \pm 5.1 \mathrm{pptv})$. For $\beta$-pinene, the model average was $13.2 \mathrm{pptv}$ compared to a measured concentration of $27.2 \mathrm{pptv}$ ( $\pm 4.5 \mathrm{pptv}$ ). Although both these days generally show model data (for the base emission rate scenario) lower than the measurements, the measured points still lie within the uncertainty of the model.

The calculated $\alpha$-pinene emission rate was, on average, $13-18 \%$ of the total monoterpenes emissions (depending on the time of day). The associated lower and upper ranges were $11-22 \%$, respectively. For $\beta$-pinene emission rates, the calculated average was $9-12 \%$ of total monoterpene emissions, ranging from $8-14 \%$ when accounting for emission uncertainties and variability. Compared to monoterpene fluxes, as shown in Fig. 9, the model agreement is much better. For $\alpha$-pinene, the model slightly underestimates the measured fluxes. The averaged simulated $\alpha$-pinene flux at the measurement height was $31.4 \mu \mathrm{g} \mathrm{m}^{-2} \mathrm{~h}^{-1}$ on $21 \mathrm{July}$, compared to 27.9 ( \pm 18.4$) \mu \mathrm{g} \mathrm{m}^{-2} \mathrm{~h}^{-1}$ measured using DEA. On 4 August, the average modeled flux was $15.2 \mu \mathrm{g} \mathrm{m}^{-2} \mathrm{~h}^{-1}$, compared to $16.8( \pm 4.4) \mu \mathrm{g} \mathrm{m}^{-2} \mathrm{~h}^{-1}$ from DEA data. For $\beta$-pinene, an average flux of $20.3 \mu \mathrm{g} \mathrm{m}^{-2} \mathrm{~h}^{-1}$ was
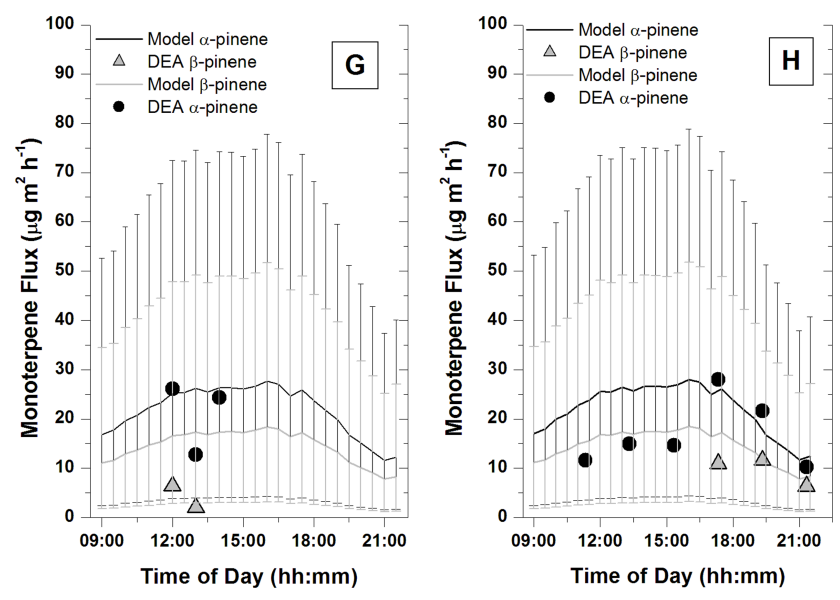

Fig. 10. Comparison of pinene and $\beta$-pinene fluxes to a 1-D atmospheric chemistry model. Again, fluxes of pinene and $\beta$ pinene compare well with the DEA measurements and are significantly within the relatively large uncertainties associated with this emission-based model.

calculated for 21 July, compared to $8.8( \pm 6.2) \mu \mathrm{g} \mathrm{m}^{-2} \mathrm{~h}^{-1}$ measured by DEA. On 4 August, the modeled average was $9.91 \mu \mathrm{g} \mathrm{m}^{-2} \mathrm{~h}^{-1}$, compared to the DEA value of $9.6( \pm 1.9) \mu \mathrm{g} \mathrm{m}^{-2} \mathrm{~h}^{-1}$. While agreement is achieved between the model and DEA measurements, the wide range of modeled concentrations and fluxes, depending on the three emissions scenarios, highlights the need for these speciated monoterpene flux measurements to better constrain models, which generally do not consider the uncertainty and variability of the emissions.

\section{Conclusions}

A new disjunct eddy accumulation (DEA) instrument was characterized, and ambient measurements of isoprene and $\alpha$-and $\beta$-pinene concentrations and fluxes were successfully made during the CABINEX campaign in the summer of 2009. Although other accumulation techniques have been used to measure BVOC fluxes above North American forests, these data are the first measurements of both isoprene and speciated monoterpene measurements using DEA. Measurements show good agreement with emission algorithms for isoprene and a simplified atmospheric chemistry 1-D model for $\alpha$ - and $\beta$-pinene concentrations and fluxes, given a range of assumed emission scenarios. Long-term monitoring of speciated monoterpenes at this site is of particular importance. This field site continues to undergo successional transition to a forest more substantially impacted by monoterpene-emitting species. Future measurements of speciated monoterpene fluxes are therefore necessary to fully understand the trends and impact on atmospheric chemistry above the forest during this transition. 
For future deployments of the DEA instrument, improvements to the sampler could be made to further utilize the advantages of this technique. As described previously, during routine operation, the sampler works by setting $w_{\max }$ to $3 \sigma$ of the previous hour's vertical wind data. Although this approach has been shown to be successful, during CABINEX very large eddy events still resulted in the sampler not being able to catch all of the updraft or downdraft, for $2.5 \%$ of the time. Improved statistical calculations and in situ modifications to the DEA software could lead to this number being reduced even further. Similarly, during field deployment, $12.2 \%$ of the time the vertical wind was below $w_{\min }$ resulting in a "null sample". The threshold of $0.66 \sigma$ does appear to have significantly altered the statistics of sampling enough to cause a systematic overestimation in the calculation of the flux. This is similar to the $\beta$ constant seen in the REA technique and leads to the need to apply a broad correction factor of $8.6 \%$ to all derived BVOCs fluxes. The application of this correction factor shows that the use of a dead-band does present a potential drawback with this variation on DEA sampling, and any future use of such dead-bands must be carefully considered in order to balance the potential issues with flow control against the introduction of such systematic errors. In addition, this "null sample" could be collected in a third sample tube that represents neither updrafts nor down drafts and is analyzed in a similar way to the "active" tubes. Such collection methods are routinely employed on REA measurements (e.g., Christiansen et al., 2000; Graus et al., 2006; Turnipseed et al., 2009). However, the current ISR and valve system would need to be modified to allow such sampling.

During this work the GC-FID detector provided high sensitivity for isoprene and some terpenes. However, other suitable detectors could be employed such as GC-MS based systems with the potential for multidimensional $\mathrm{MS}^{n}$ analysis that has the ability to determine both the parent ion and fragments of these ions. This analytical capability could be used in future experiments to detect other compounds of interest via DEA, such as the isoprene oxidation products MVK and MCAR. However, it is typically more difficult to achieve high precision with these detectors when compared to the FID. Although there are still developments and improvements possible in the DEA/TD-4/GC-FID detector, in its current configuration, this instrument has shown the potential of this method as a field-portable micrometeorological instrument for the fast and accurate measurement of atmospheric BVOC concentrations and fluxes.

Acknowledgements. The authors would like to thank Kimberly Hill Edwards, Steve Bertman, Mary Ann Carroll and the University of Michigan Biological Station for logistic support and all the CABINEX campaign participants for the free use of their data. The technical help of Detlev Helmig for use of emission data used to parameterize the model, Andrew Turnipseed with respect to the use of of a dead-band threshold and its application to DEA and the Jonathan Amy Facility for Chemical Instrumentation at Purdue for construction of the sampler is greatly appreciated. The authors also would like to acknowledge the helpful comments of the several anonymous reviewers who have helped significantly improve the manuscript. This work was funded partly funded by Eastern Michigan University New Faculty "start-up" (Edwards), by Eastern Michigan University Provosts Faculty Research Award (Edwards) and by NSF grant \# 0904151. K. A. Pratt is grateful for funding from a NOAA climate and global change postdoctoral fellowship.

Edited by: E. C. Apel

\section{References}

Ammann, C. and Meixner, F. X.: Stability dependence of the relaxed eddy accumulation coefficient for various scalar quantities, J. Geophys. Res., 107, 8083, doi:10.1029/2001JD000649, 2002.

Andreae, M. O. and Crutzen, P. J.: Atmospheric aerosols: biogeochemical sources and role in atmospheric chemistry, Science, 76, 1052-1058, 1997.

Apel, E. C., Riemer, D. D., Hills, A., Baugh, W., Orlando, J., Faloona, I., Tan, D., Brune, W., Lamb, B., Westberg, H., Carroll, M. A., Thornberry, T., and Geron, C. D.: Measurement and interpretation of isoprene fluxes and isoprene, methacrolein, and methyl vinyl ketone mixing ratios at the Prophet site during the 1998 intensive, J. Geophys. Res., 107, 4034, doi:10.1029/2000JD000225, 2001.

Arneth, A., Monson, R. K., Schurgers, G., Niinemets, Ü., and Palmer, P. I.: Why are estimates of global terrestrial isoprene emissions so similar (and why is this not so for monoterpenes)?, Atmos. Chem. Phys., 8, 4605-4620, doi:10.5194/acp-8-46052008, 2008.

Atkinson, R., Baulch, D. L., Cox, R. A., Crowley, J. N., Hampson, R. F., Hynes, R. G., Jenkin, M. E., Rossi, M. J., Troe, J., and IUPAC Subcommittee: Evaluated kinetic and photochemical data for atmospheric chemistry: Volume II - gas phase reactions of organic species, Atmos. Chem. Phys., 6, 3625-4055, doi:10.5194/acp-6-3625-2006, 2006.

Baldocchi, D., Guenther, A., Harley, P., Klinger, L., Zimmerman, P., Lamb, B., and Westberg, H.: The fluxes and air chemistry of isoprene above a deciduous hardwood forest, Philos. T. Roy. Soc., 351, 279-296, 1995.

Barket, D. J., Hurst, J. M., Couch, T. L., Colorado, A., Shepson, P. B., Riemer, D. D., Hills, A. J., Apel, E. C., Hafer, R., Lamb, B. K., Westberg, H. H., Farmer, C. T., Stabenau, E. R., and Zika, R. G.: Intercomparison of automated methodologies for determination of ambient isoprene during the PROPHET 1998 summer campaign, J. Geophys. Res., 106, 24301, doi:10.1029/2000JD900562, 2001.

Bergen, K. M. and Dronova, I.: Observing succession on aspendominated landscapes using a remote sensing-ecosystem approach, Landscape Ecol., 22, 1395-1410, 2007.

Bertman, S. B., Caroll, M. A., Stevens, P., and Shepson, P. B.: Overview of the combined atmosphere-biosphere intensive experiment (CABINEX), in preparation, 2012.

Biesenthal, T. A., Wu, Q., Shepson, P. B., Wiebe, H. A., Anlauf, K., and Mackays, K.: Observations of anthropogenic inputs of the isoprene oxidation products methyl vinyl ketone 
and methacrolein to the atmosphere, Atmos. Environ., 31, 2049, doi:10.1016/S1352-2310(96)00318-4, 1997.

Bowling, D. R., Delany, A. C., Turnipseed, A. A., Baldocchi, D. D., and Monson, R. K.: Modification of the relaxed eddy accumulation technique to maximize measured scalar mixing ratio differences in updrafts and downdrafts, J. Geophys. Res., 104, 9121-9133, 1999.

Calogirou, A., Larsen, B. R., Brussol, C., Duane, M., and Kotzias, D.: Decomposition of terpenes by ozone during sampling on Tenax, Anal. Chem., 68, 1499-1506, 1996.

Carroll, M. A., Bertman, S. B., and Shepson, P. B.: Overview of the Program for Research on Oxidants: PHotochemistry, Emissions, and Transport (PROPHET) summer 1998 measurements intensive, J. Geophys. Res., 106, 24275, doi:10.1029/2001JD900189, 2001.

Chamedies, W. L. and Walker, J. C. G.: A photochemical theory for tropospheric ozone, J. Geophys. Res., 78, 8751-8760, 1973.

Christensen, C. S., Hummelshoj, P., Jensen, N. O., Larsen, B., Lohse, C., Pilegaard, K., and Skov, H.: Determination of the terpene ?ux from orange species and Norway spruce by relaxed eddy accumulation, Atmos. Environ., 34, 3057-3067, 2000.

Dettmer, K. and Engewald, W.: Adsorbent materials commonly used in air analysis for adsorptive enrichment and thermal desorption of volatile organic compounds, Anal. Bio. Chem., 373, 490-500, 2002.

DiCarlo, P., Brune, W. H., Martinez, M., Harder, H., Lescher, R., Ren, X., Thornberry, T., Carroll, M. A., Young, V., Shepson, P. B., Riemer, D., and Apel, E.: Missing OH Reactivity in a Forest: Evidence for Unknown Reactive Biogenic VOCs, Science, 304, 722-725, 2004.

Dusanter, S., Vimal, D., Stevens, P. S., Volkamer, R., and Molina, L. T.: Measurements of $\mathrm{OH}$ and $\mathrm{HO}_{2}$ concentrations during the MCMA-2006 field campaign - Part 1: Deployment of the Indiana University laser-induced fluorescence instrument, Atmos. Chem. Phys., 9, 1665-1685, doi:10.5194/acp-9-1665-2009, 2009.

Edwards, G. D., Shepson, P. B., Grossenbacher, J., Wells, J. M., Patterson, G. E., Barkett, D. J., Preesley, S., Karl, T., and Apel, E.: Development of an automated cylindrical ion trap mass spectrometer for the determination of atmospheric volatile organic compounds, Anal. Chem., 79, 5040-5050, 2007.

Fick, J., Pommer, L., Andersson, B., and Nilsson, C.: Ozone removal in the sampling of parts per billion levels of terpenoid compounds: An evaluation of different scrubber materials, Environ. Sci. Technol., 35, 1458-1462, 2001.

Fuentes, J. D., Hayden, B. P., Garstang, M., Lerdau, M., Fitzjarrald, D., Baldocchi, D. D., Monson, R., Lamb, B., and Geron, C.: New Directions: VOCs and biosphere-atmosphere feedbacks, Atmos. Environ., 35, 189-191, 2001.

Graus, M., Hansel, A., Wisthaler, A., Lindinger, C., Forkel, R., Hauff, K., Klauer, M., Pfichner, A., Rappengluck, B., Steigner, D., and Steinbrecher, R.: A relaxed-eddy-accumulation method for the measurement of isoprenoid canopy-fluxes using an online gas-chromatographic technique and PTR-MS simultaneously, Atmos. Environ. 40, S43-S54, 2006.

Griffin, R. J., Cocker, D. R., Seinfeld, J. H., and Dabdub, D.: Estimate of global atmospheric organic aerosol from oxidation of biogenic hydrocarbons, Geophys. Res. Lett., 26, 2421-2724, 1999.
Grossman, R. L.: Sampling errors in the vertical fluxes of potential temperature and moisture measured by aircraft during FIFE, J. Geophys. Res., 97, 18439-18443, 1992.

Guenther, A. B., Monson, R. K., and Fall, R.: Isoprene and monoterpene emission rate variability - observations with eucalyptus and emission rate algorithm development, J. Geophys. Res., 96, 10799-10808, 1991.

Guenther, A. B., Zimmerman, P. R., Harley, P. C., Monson, R. K., and Fall, R.: Isoprene and monoterpene emission rate variability - model evaluations and sensitivity analyses, J. Geophys. Res., 98, 12609-12617 1993.

Guenther, A. B., Hewitt, C. N., Erickson, D., Fall, R., Geron, C., Graedel, T., Harley, P., Klinger, L., Lerdau, M., Mckay, W. A., Pierce, T., Scholes, B., Steinbrecher, R., Tallamraju, R., Taylor, J., and Zimmerman P.J.: A global-model of natural volatile organic-compound emissions, J. Geophys. Res., 100, 8873, doi:10.1029/94JD02950, 1995.

Guenther, A. B., Baugh, W., Davis, K., Hampton, G., Harley, P. Klinger, L., Vierling, L., Zimmerman, P., Baldocchi, D., Geron, C., and Pierce, T.: Isoprene fluxes measured by enclosure, relaxed eddy accumulation, surface layer gradient, mixed layer gradient, and mixed layer mass balance techniques, J. Geophys. Res., 101, 18555-18567, 1996.

Harrison, D., Hunter, M. C., Lewis, A. C., Seakins, P. W., Nunes, T. V., and Pio, C. A.: Ambient isoprene and monoterpene concentrations in a greek fir forest, reconciliation with emissions measurements and effects on measured $\mathrm{OH}$ concentrations, Atmos. Environ., 35, 4687, doi:10.1016/S1352-2310(01)00091-7, 2001.

Helmig, D.: Ozone removal techniques in the sampling of atmospheric volatile organic trace gases, Atmos. Environ. 31, 36363651, 1997.

Helmig, D.: Air analysis by gas chromatography, J. Chromogr. A, 843, 129-146, doi:10.1016/S0021-9673(99)00173-9, 1999.

Hicks, B. B. and McMillen, R. T.: A Simulation of eddy accumulation method for measuring pollutant fluxes, J. Clim. Appl. Meteorol., 23, 637-643, 1984.

Hurst, J. M., Barket, D. J., Herrera-Gomez, O., Couch, T. L., Shepson, P. B., Faloona, I., Tan, D., Brune, W., Westberg, H., Lamb, B., Biesenthal, T., Young, V., Goldstein, A., Munger, J. W., Thornberry, T., and Carroll, M. A.: Investigation of the nighttime decay of isoprene, J. Geophys. Res., 106, 24335-24346, 2001.

Karl, T. and Guenther, A.: Atmospheric variability of biogenic vocs in the surface layer measured by proton-transfer-reaction mass spectrometry, Int. J. Mass Spectrom., 239, 77-86, 2004.

Kavouras, I. G., Mihalopoulos, N., and Stephanou, E.G.: Formation and gas/particle partitioning of monoterpenes photooxidation products over forests, Geophys. Res. Lett., 26, 55-58, 1999.

Kesselmeier, J. and Staudt, M.: Biogenic volatile organic compounds (VOC): An overview on emission, physiology and ecology, J. Atmos. Chem., 33, 23-88, 1999.

Kim, S., Karl, T., Helmig, D., Daly, R., Rasmussen, R., and Guenther, A.: Measurement of atmospheric sesquiterpenes by proton transfer reaction-mass spectrometry (PTR-MS), Atmos. Meas. Tech., 2, 99-112, doi:10.5194/amt-2-99-2009, 2009.

Komenda, M., Parusel, E., Wedel, A., and Koppmann, R.: Measurements of biogenic VOC emissions: sampling, analysis and calibration, Atmos. Environ., 35, 2069-2080, 2001. 
Kuhn, U., Andreae, M. O., Ammann, C., Araújo, A. C., Brancaleoni, E., Ciccioli, P., Dindorf, T., Frattoni, M., Gatti, L. V., Ganzeveld, L., Kruijt, B., Lelieveld, J., Lloyd, J., Meixner, F. X., Nobre, A. D., Pöschl, U., Spirig, C., Stefani, P., Thielmann, A., Valentini, R., and Kesselmeier, J.: Isoprene and monoterpene fluxes from Central Amazonian rainforest inferred from towerbased and airborne measurements, and implications on the atmospheric chemistry and the local carbon budget, Atmos. Chem. Phys., 7, 2855-2879, doi:10.5194/acp-7-2855-2007, 2007.

Lee, A., Schade, G. W., Holzinger, R., and Goldstein, A. H.: A comparison of new measurements of total monoterpene flux with improved measurements of speciated monoterpene flux, Atmos. Chem. Phys., 5, 505-513, doi:10.5194/acp-5-505-2005, 2005.

Lenschow, D. H., Mann, J., and Kristensen, L., How long is long enough when measuring fluxes and other turbulence statistics?, J. Atmos. Ocean. Tech., 11, 661-673, 1994.

Loreto, F.: Emission of isoprenoids by plants: Their role in atmospheric chemistry, response to the environment, and biochemical pathways, J. Environ. Path Tox Oncol., 16, 119-124, 1997.

Mahrt, L: Flux Sampling Errors for Aircraft and Towers, J. Atmos. Ocean. Tech., 15, 416-429, 1998.

Makela, J. M., Aalto, P., Jokinen, V., Pohja, T., Nissinen, A., Palmroth, S., Markkanen, T., Seitsonen, K., Lihavainen, H., and Kulmala, M.: Observations of Ultrafine Aerosol Particle Formation and Growth in Boreal Forest, Geophys. Res. Lett., 24, 1219$1222,1997$.

Martins, D.: Development of methods for measurement of biosphere-atmosphere exchange of carbon and nitrogen, Ph.D. Thesis, Purdue University, 2008.

Mielke, L. H., Pratt, K. A., Shepson, P. B., McLuckey, S. A., Wisthaler, A., and Hansel, A.: Quantitative determination of biogenic volatile organic compounds in the atmosphere using proton-transfer reaction linear ion trap mass spectrometry, Anal. Chem., 82, 7952-7957, 2010.

Misztal, P. K., Heal, M. R., Nemitz, E., and Cape, J. N.: Development of PTR-MS selectivity for structural isomers: Monoterpenes as a case study, Int. J. Mass Spectrom., 310, 10-19, doi:10.1016/j.ijms.2011.11.001, 2012.

Müller, M., Mielke, L. H., Breitenlechner, M., McLuckey, S. A., Shepson, P. B., Wisthaler, A., and Hansel, A.: MS/MS studies for the selective detection of isomeric biogenic VOCs using a Townsend Discharge Triple Quadrupole Tandem MS and a PTR-Linear Ion Trap MS, Atmos. Meas. Tech., 2, 703-712, doi:10.5194/amt-2-703-2009, 2009.

Oncley, S., Delany, A., Horst, T., and Tans, P.: Verification of flux measurement using relaxededdy accumulation, Atmos. Environ. A, 27, 2417-2426, 1993.

Ortega, J., Helmig, D., Guenther, A., Harley, P., Pressley, S., and Vogel, C.: Flux estimates and $\mathrm{OH}$ reaction potential of reactive biogenic volatile organic compounds (BVOCs) from a mixed northern hardwood forest, Atmos. Environ., 41, 5479-5495, 2007.

Ortega, J., Helmig, D., Daly, R. W., Tanner, D. M., Guenther, A. B., and Herrick, J. D.: Approaches for quantifying reactive and low-volatility biogenic organic compound emissions by vegetation enclosure techniques - Part B: Applications, Chemosphere, 72, 365-380, 2008.

Pattey, E., Desjardins, R. L., and Rochette, P.: Accuracy of the relaxed eddy-accumulation technique, evaluated using $\mathrm{CO}_{2}$ flux measurements, Bound.-Lay. Meteorol., 66, 341-355, 1993.
Pattey, E., Desjardins, R. L., Westberg, H., Lamb, B., and Zhu, T.: Measurement of isoprene emissions over a black spruce stand using a tower-based relaxed eddy-accumulation system, J. Appl. Meteorol., 38, 870-877, doi:10.1175/15200450(1999)038<0870:MOIEOA > 2.0.CO;2, 1999.

Pratt, K. A., Mielke, L. H., Shepson, P. B., Bryan, A. M., Steiner, A. L., Ortega, J., Daly, R., Helmig, D., Vogel, C. S., Griffith, S., Dusanter, S., Stevens, P. S., and Alaghmand, M.: Contributions of individual reactive biogenic volatile organic compounds to organic nitrates above a mixed forest, Atmos. Chem. Phys. Discuss., 12, 17031-17086, doi:10.5194/acpd-12-17031-2012, 2012.

Pressley, S., Lamb, B., Westberg, H., and Vogel, C.: Relationships among canopy scale energy fluxes and isoprene flux derived from long-term, seasonal eddy covariance measurements over a hardwood forest, Agr. Forest Meteorol., 136, 188-202, 2006.

Ren, X., Sanders, J. E., Rajendran, A., Weber, R. J., Goldstein, A. H., Pusede, S. E., Browne, E. C., Min, K.-E., and Cohen, R. C.: A relaxed eddy accumulation system for measuring vertical fluxes of nitrous acid, Atmos. Meas. Tech., 4, 2093-2103, doi:10.5194/amt-4-2093-2011, 2011.

Rinne, H. J. I., Delany, A. C., Greenberg, J. P., and Guenther, A. B.: A true eddy accumulation system for trace gas fluxes using disjunct eddy sampling method, J. Geophys. Res., 105, 2479124798, 2000.

Rinne, H. J. I., Guenther, A. B., Greenberg, J. P., and Harley, P. C.: Isoprene and monoterpene fluxes measured above amazonian rainforest and their dependence on light and temperature, Atmos. Environ., 36, 2421-2426, 2002.

Rinne, J., Ammann, C., 2012. Disjunct Eddy Covariance Method, in: Aubinet, Eddy Covariance Handbook, edited by: Vesala, M. T. and Papale, D., Springer, 289-305, 2012.

Shallcross, D. E. and Monks, P. S.: New Directions: A role for isoprene in biosphereclimate-chemistry feedbacks, Atmos. Environ., 34, 1659-1660, 2000.

Simon, V., Riba, M., Waldhart, A., and Torres, L.: Breakthrough volume of monoterpenes on Tenax TA - Influence of temperature and concentration for alpha-pinene, J. Chromatogr. A, 704, 465471, 1995.

Stearns, F. and Likens, G. E.: One hundred years of recovery of a pine forest in northern Wisconsin, Am. Midland Nat., 148, 2-19, 2002.

Tani, A., Nozoe, S., Aoki, M., and Hewitt, C. N.: Monoterpene Fluxes measured above a Japanese red pine forest at Oshiba Plateau, Japan, Atmos. Environ., 36, 3391-3402, 2002.

Turnipseed, A. A., Pressley, S. N., Karl, T., Lamb, B., Nemitz, E., Allwine, E., Cooper, W. A., Shertz, S., and Guenther, A. B.: The use of disjunct eddy sampling methods for the determination of ecosystem level fluxes of trace gases, Atmos. Chem. Phys., 9, 981-994, doi:10.5194/acp-9-981-2009, 2009.

Warneke, C., Kato, S., De Gouw, J. A., Goldan, P. D., Kuster, W. C., Shao, M., Lovejoy, E. R., Fall, R., and Fehsenfeld, F. C.: Online volatile organic compound measurements using a newly developed proton-transfer ion-trap mass spectrometry instrument during New England Air Quality Study - Intercontinental Transport and Chemical Transformation 2004: Performance, intercomparison, and compound identification, Environ. Sci. Technol., 39, 5390-5397, 2005. 
Westberg, H., Lamb, B., Hafer, R., Hills, A., Shepson, P. B., and Vogel, C.: Measurement of isoprene fluxes at the PROPHET site, J. Geophys. Res., 106, 24347-24358, 2001.

Wilczak, J. M., Oncley, S. P., and Stage, S.: Sonic anemometer tilt correction algorithms, Bound.-Lay. Meteorol., 99, 127-150, 2001.
Zhang, R., Suh, I., Clinkenbeard, A. D., Lei, W., and North, S. W.: Kinetic studies of $\mathrm{OH}$-initiated reactions of isoprene, J. Geophys. Res., 105, 24627-24635, 2000. 